\title{
FGF13 promotes metastasis of triple-negative breast cancer
}

Cameron N. Johnstone 1,2,3,4,5,6,10,11, Andrew D. Pattison 6,7, Paul F. Harrison ${ }^{8}$, David R. Powell 7,8, Peter Lock ${ }^{9}$, Matthias Ernst 4,5, Robin L. Anderson 1,2,3,4,5,10,11, and Traude H. Beilharz ${ }^{6,7,8,10,11}$

1. Cancer Research Division, Peter MacCallum Cancer Centre, Victorian Comprehensive Cancer Centre, Parkville, Victoria, Australia

2. Sir Peter MacCallum Department of Oncology, University of Melbourne, Parkville, Victoria, Australia

3. Department of Clinical Pathology, University of Melbourne, Parkville, Victoria, Australia

4. Olivia Newton-John Cancer Research Institute, Heidelberg, Victoria, Australia

5. School of Cancer Medicine, La Trobe University, Bundoora, Victoria, Australia

6. Department of Biochemistry and Molecular Biology, Monash University, Clayton, Victoria, Australia

7. Biomedicine Discovery Institute, Monash University, Clayton, Victoria, Australia

8. Monash Bioinformatics Platform, Monash University, Clayton, Victoria, Australia

9. LIMS Bioimaging Facility, La Trobe Institute for Molecular Science, La Trobe University, Bundoora, Victoria, Australia

10. These authors are co-senior authors

11. To whom correspondence should be addressed.

Cameron N. Johnstone, Olivia Newton-John Cancer Research Institute, 145 Studley Road, Heidelberg, 3084 Victoria, Australia. Email: cameron.johnstone@onjcri.org.au

Robin L. Anderson, Olivia Newton-John Cancer Research Institute, 145 Studley Road, Heidelberg, 3084 Victoria, Australia. Email: robin.anderson@onjcri.org.au

Traude H. Beilharz, RNA Systems Biology Laboratory, Department of Biochemistry and Molecular Biology, Monash University, Clayton, 3800, Victoria, Australia. Email: traude.beilharz@monash.edu

This is the author manuscript accepted for publication and has undergone full peer review but has not been through the copyediting, typesetting, pagination and proofreading process, which may lead to differences between this version and the Version of Record. Please cite this article as doi: $10.1002 / \mathrm{ijc} .32874$

This article is protected by copyright. All rights reserved. 
This article is protected by copyright. All rights reserved. 
Running title: Upregulation of FGF13 drives breast cancer metastasis

Key words: triple-negative breast cancer, metastasis, mouse model, xenograft, FGF13

Abbreviations: BLI, bioluminescence imaging. FGF, fibroblast growth factor. FHF, fibroblast growth factor homologous factor. GFP, green fluorescent protein. HER2, human epidermal growth factor receptor 2, qRT-PCR, quantitative reverse transcription-polymerase chain reaction. TNBC, triplenegative breast cancer. UPR, unfolded protein response.

Article Category: Molecular Cancer Biology

\section{Novelty and Impact:}

We conducted RNA expression analysis on four isogenic MDA-MB-231 TNBC tumour models that differed in metastatic capacity. Here we identify FGF13 upregulation in metastatic MDA-MB-231 variants. Higher FGF13 expression was associated with worse survival in patients with basal-like breast cancer and knockdown of FGF13 in MDA-MB-231_HM cells markedly reduced spontaneous metastasis to liver and lung in mice without affecting primary xenograft growth. Our results indicate that FGF13 could be a novel target for anti-metastasis therapy.

This article is protected by copyright. All rights reserved. 


\section{ABSTRACT}

Triple-negative breast cancer (TNBC) represents $10-20 \%$ of all human ductal adenocarcinomas and has a poor prognosis relative to other subtypes, due to the high propensity to develop distant metastases. Hence, new molecular targets for therapeutic intervention are needed for TNBC.

We recently conducted a rigorous phenotypic and genomic characterization of four isogenic populations of MDA-MB-231 human triple-negative breast cancer cells that possess a range of intrinsic spontaneous metastatic capacities in vivo, ranging from non-metastatic (MDA-MB231_ATCC) to highly metastatic to lung, liver, spleen and spine (MDA-MB-231_HM).

Gene expression profiling of primary tumours by RNA-Seq identified the fibroblast growth factor homologous factor, FGF13, as highly upregulated in aggressively metastatic MDA-MB-231_HM tumours. Clinically, higher FGF13 mRNA expression was associated with significantly worse relapse free survival in both luminal $A$ and basal-like human breast cancers but was not associated with other clinical variables and was not upregulated in primary tumours relative to normal mammary gland. Stable FGF13 depletion restricted in vitro colony forming ability in MDA-MB-231_HM TNBC cells but not in oestrogen receptor (ER) positive MCF-7 or MDA-MB-361 cells. However, despite augmenting MDA-MB-231_HM cell migration and invasion in vitro, FGF13 suppression almost completely blocked the spontaneous metastasis of MDA-MB-231_HM orthotopic xenografts to both lung and liver while having negligible impact on primary tumour growth.

Together, these data indicate that FGF13 may represent a therapeutic target for blocking metastatic outgrowth of certain TNBCs. Further evaluation of the roles of individual FGF13 protein isoforms in progression of the different subtypes of breast cancer is warranted. 


\section{INTRODUCTION}

Triple-negative breast cancer (TNBC) displays the worst outcome of all breast cancer clinical subtypes due to its propensity for early relapse and development of resistance to chemotherapeutic drugs. ${ }^{1-3}$ New therapies that target the key molecular alterations found in TNBC are therefore required. However, the elucidation of new molecular targets for TNBC is complicated by considerable inter- and intra-tumour heterogeneity and gene expression analyses have revealed at least four distinct subtypes at the molecular level, which include basal-1 (BL1), basal-2 (BL2), mesenchymal (M) and luminal androgen receptor-positive (LAR). ${ }^{4-8}$

We recently compared the gene expression profiles of primary orthotopic xenografts formed by four different isogenic variants of the mesenchymal-type MDA-MB-231 human TNBC line in immunodeficient mice. ${ }^{9}$ The four models differ in their abilities to spontaneously metastasize from the inguinal mammary gland to regional lymph nodes and to distant organs and possessed either no (231_ATCC), an intermediate (231_LNA, 231_LM2), or a high (231_HM.LNm5) intrinsic capacity to metastasize.

The fibroblast growth factor-13 (FGF13) gene was particularly over-expressed in the highly metastatic 231_HM.LNm5 line. ${ }^{9}$ FGF13 encodes one of four FGF homologous factors (FHFs) found in vertebrates. ${ }^{10,11}$ FGF13 is located on human chromosome Xq26 and can produce six transcript variants, encoding five unique protein isoforms. While the four FHFs (FGF11-FGF14) share sequence homology with bona-fide FGFs, they are more highly related to each other, lack key amino acids required for FGF receptor binding, and share an intracellular localization. ${ }^{10}$ While primarily expressed by neurons, ${ }^{12}$ increased levels of FGF13 has been observed in several different tumour types ${ }^{13-18}$, but the function(s) of the protein in cancer cells are only beginning to be ascertained. ${ }^{17,19}$

In this study, levels of total FGF13 mRNA as well as of individual transcript variants were tested for associations with clinical parameters and patient outcome in invasive breast ductal adenocarcinoma. Stable suppression of FGF13 was achieved in 231_HM.LNm5, as well as in MDAMB-361 and MCF-7 breast cancer cell lines. Depletion of FGF13 enhanced in vitro migration and 
invasion of metastatic 231_HM.LNm5 cells but reduced colony forming ability without affecting cell proliferation. Moreover, despite the observed augmentation of cell motility, reduction of FGF13 almost completely blocked the spontaneous metastasis of 231_HM.LNm5 orthotopic mammary tumours to the lung and liver in mice, while having negligible impact on primary tumour growth. Together, these data indicate that FGF13 may represent a target for anti-metastasis therapy in the TNBCs in which it is over-expressed. 


\section{MATERIALS AND METHODS}

\section{Cell culture}

The MDA-MB-231 human breast adenocarcinoma cell line was purchased from $\mathrm{ATCC}^{20}$ and designated 231_ATCC. The MDA-MB-231_LM2 variant (231_LM2) (also designated clone 4175) was a kind gift from Joan Massague (Memorial Sloan-Kettering Cancer Centre, USA). ${ }^{21}$ The MDA-MB231_LNA (231_LNA) line was isolated from a spontaneous lymph node metastasis that arose in a mouse inoculated orthotopically with a reporter gene tagged version of late-passage MDA-MB-231_I cells. ${ }^{9,} 22$ MDA-MB-231_HM cells ${ }^{23,} 24$ were kindly provided by ZM Shao and ZL Ou (Breast Cancer Institute, Fudan University, Shanghai, China). The MDA-MB-231HM.LNm5 (231_HM.LNm5) variant was derived as described. ${ }^{9}, 25$ The MDA-MB-361scid line was isolated from a primary tumour that formed in a BALB/c-scid mouse inoculated with parental MDA-MB-361 cells. SUM149 and SUM159 were kindly provided by Steve Ethier (University of Michigan, USA). Other human breast cancer lines were obtained from ATCC. The Research Resource IDentifiers (RRID) as available in the ExPASy Cellosaurus database (https://web.expasy.org/cellosaurus/) are provided for each cell line used as follows: MDA-MB-231 parental (RRID:CVCL_062), MDA-MB-231_LNA (N/A), MDA-MB231_LM2_4175 (RRID:CVCL_5998), MDA-MB-231_HM (N/A), MDA-MB-231_HM.LNm5 (N/A), MDAMB-361 (RRID:CVCL_0620), MDA-MB-361scid (N/A), MCF-10A (RRID:CVCL_0598), MCF-7 (RRID:CVCL_0031), SUM149PT (RRID:CVCL_342), SUM159PT (RRID:CVCL_5423), T-47D (RRID:CVCL_0553), MDA-MB-415 (RRID:CVCL_0621), ZR-75-1 (RRID:CVCL_0588), ZR-75-30 (RRID:CVCL_1661), MDA-MB-175VII (RRID:CVCL_1400), CAMA-1 (RRID:CVCL_1115), BT-474 (RRID:CVCL_0179), SK-BR-3 (RRID:CVCL_0033), MDA-MB-453 (RRID:CVCL_0418), HCC1419 (RRID:CVCL_1251), Hs578T (RRID:CVCL_0332), DU4475 (RRID:CVCL_1183), CAL-120 (RRID:CVCL_1104), MDA-MB-468 (RRID:CVCL_0419), UACC-812 (RRID:CVCL_1781), BT-549 (RRID:CVCL_1092).

All lines were maintained in Dulbecco's Modified Eagle medium (DMEM) (Thermo Fisher Scientific, Scoresby, Vic, Australia) supplemented with 10\% (v/v) heat-inactivated foetal bovine serum

This article is protected by copyright. All rights reserved. 
(FBS, Thermo Fisher Scientific), 2mM L-glutamine, 1\% (v/v) non-essential amino acids, 5\% (v/v) sodium pyruvate, penicillin $(100 \mathrm{IU} / \mathrm{ml})$ and streptomycin $(100 \mu \mathrm{g} / \mathrm{ml})$. Cells were maintained at $37^{\circ} \mathrm{C}$ in $5 \% \mathrm{CO}_{2}(\mathrm{v} / \mathrm{v})$ in air and sub-cultured every $4-5$ days. For 3D culture, cells were seeded onto a solid basement membrane gel (50\% Cultrex in full medium (Trevigen, Gaithersburg, MD, USA). MDA-MB231 derived cell lines were verified for authenticity using the AmpFLSTR ${ }^{\mathrm{TM}}$ Identifiler ${ }^{\mathrm{TM}}$ PCR Amplification Kit (Thermo Fisher Scientific) at CellBank Australia (http://www.cellbankaustralia.com). All other human cell lines were authenticated using the GenePrint ${ }^{\circledR} 10$ System (Promega Corporation, Alexandria, NSW), at the QIMR Berghofer Medical Research Institute, Australia. Cell lines were considered authentic if $>80 \%$ of measured alleles matched those of the repository sample. The STR similarity search tool (v1.1.1) was used to calculate authenticity (https://web.expasy.org/cellosaurus-str-search/). All cell lines were authenticated within the past three years. All cell lines were confirmed to be free of mycoplasma contamination before use.

\section{Generation of stable FGF13 knockdown cell lines}

To generate breast cancer lines suitable for in vivo bioluminescent imaging (BLI), the MDA-MB231HM and MDA-MB-361scid lines were transduced with the pFBneoLUC retroviral vector encoding Firefly luciferase and selected with G418 as previously described. ${ }^{22}$ The MCF-7 line was transduced with the pMSCV_Luc2-ires-mCherry retroviral vector, ${ }^{26}$ which encodes luciferase 2 and mCherry fluorescent protein. mCherry-positive single cell clones were generated by flow cytometry (FACS ARIAIII, Beckton Dickinson, Scoresby, Vic, Australia). Following in vitro expansion, nine clones positive for both mCherry expression and luciferase activity (data not shown) were pooled thereby yielding the MCF7luc2cherry cell line. pGIPZ lentiviral plasmids (Dharmacon, GE Life Sciences, Lafayette, CO, USA) encoding eGFP and a short hairpin RNA (shRNA) sequence specific for human FGF13 (shFGF13_1, Clone ID: V3LHS_409644; shFGF13_2, Clone ID: V3LHS_367912; shFGF13_3, Clone ID: V3LHS_367913) or a scrambled non-silencing control sequence (designated shNC) were obtained from the Victorian Centre for Functional Genomics (VCFG). Lentiviruses were prepared using a 2nd generation packaging system. Briefly, 293T cells were transiently transfected with the

This article is protected by copyright. All rights reserved. 
pCMV-deltaR8.2 packaging plasmid (a gift from Didier Trono, Addgene plasmid \# 12263) and pCMVVSV-G encoding the envelope protein from vesicular stomatitis virus (a gift from Robert Weinberg (Addgene plasmid \# 8454) to produce pseudotyped lentivirus. Target cells (231HMneoLUC, 361scidneoLUC and MCF7luccherry) were spin-infected (2x 45min) and transduced cells selected using puromycin dihydrochloride $(10 \mu \mathrm{g} / \mathrm{ml})$ followed by one round (361scidneoLUC_shFGF13) or two rounds (231HMneoLUC_shFGF13) of sorting for turboGFP expression by flow cytometry (FACSAria II, Beckton Dickinson). Cells were maintained in puromycin $(5 \mu \mathrm{g} / \mathrm{ml})$.

\section{D in vitro proliferation assays}

For 3D assays, cells (2,000/well) were seeded onto bovine type I collagen $(2.5 \mathrm{mg} / \mathrm{ml})$ gels (PureCol, Advanced BioMatrix, Carlsbad, CA, USA) prepared in white 96 well tissue culture plates. The luciferase-based Cell Titer Glo protocol (Promega) was used in accordance with manufacturer's instructions and a $0.1 \mathrm{~s}$ luminometer integration time.

\section{Colony forming assays in vitro}

Viable GFP-expressing cells were seeded into 6 well tissue culture plates (200/well) using a flow cytometer (FACSAria II, Beckton Dickinson) and cultured in full medium for 2 weeks (231HMneoLUC transfectants) or 4 weeks (361scidneoLUC and MCF7luc2cherry transfectants). Colonies were fixed and stained with crystal violet solution (0.5\%) and counted using $\mathrm{NIH}$ Image $\mathrm{J}$ software.

\section{Analysis of sensitivity to cisplatin in vitro}

Cells $\left(2,000\right.$ in $100 \mu l /$ well) were seeded into Nunc ${ }^{\text {TM }}$ Edge 2.096 well tissue culture plates (Thermo Fisher Scientific) and treated with 10 different doses of cisplatin (Hospira, Melbourne, Vic, Australia) for $4 \mathrm{~d}$. Viable cells were detected using the Resazurin fluorescence-based method, ${ }^{27}$ and an EnSight $^{\mathrm{TM}}$ multimode plate reader (PerkinElmer, Glen Waverley, Vic, Australia). Cisplatin $\mathrm{IC}_{50}$ values $(\mu \mathrm{M})$ were determined using non-linear regression analysis (GraphPad Prism software v7).

This article is protected by copyright. All rights reserved. 


\section{In vitro analysis of cell motility}

Transwell migration and invasion assays were conducted as described previously. ${ }^{28}$ Briefly, $2 \times 10^{5}$ cells were seeded into the upper chamber of Fluoroblok $(8 \mu \mathrm{M}$ membrane pore size) inserts (Corning Life Sciences, Oneonta, NY, USA) in serum-free medium. Cells were allowed to migrate (21h) or invade $(24 \mathrm{~h})$ toward $10 \%$ serum-containing medium $(700 \mu \mathrm{l})$ in the base of the unit. For invasion assays, cells were first mixed with Cultrex (Trevigen) and the mixture $(200 \mu \mathrm{l}$ of Cultrex (50\% final)) dispensed into the insert and allowed to gel at $37^{\circ} \mathrm{C}$ prior to commencement of the assay. Inserts were incubated with $4 \mu \mathrm{g} / \mathrm{ml}$ calcein ${ }^{\mathrm{AM}}$ (Enzo Biochem Inc., New York, NY) prior to imaging and counting of cells.

\section{Quantitative real-time RT-PCR (qRT-PCR)}

Total RNA was isolated from breast cancer cell lines cultured in 2D using either the Direct-zol RNA mini kit (Zymo Corporation, Irvine, CA, USA) or the RNeasy mini kit (Qiagen, Chadstone, Vic, Australia), both featuring on-column DNase I digestion. Total RNA was isolated from 3D cultures using TRIzol reagent (Thermo Fisher Scientific). RNA was recovered either from whole primary tumours or from viable fluorescent reporter-positive cancer cells sorted from digested tumours by flow cytometry as described previously. ${ }^{9}$ Resected whole xenograft tumours were homogenized in TRIzol reagent (Thermo Fisher Scientific) using a PowerLyzer 24 (Qiagen) and passed through a $21 \mathrm{G}$ needle several times prior to total RNA isolation. First strand cDNA was oligo dT-primed and synthesized from $5 \mu \mathrm{g}$ total RNA with M-MLV reverse transcriptase in a $20 \mu$ l reaction volume (Promega). One-step (using 4x Fast Virus Master Mix and 50ng total RNA template per reaction) or two-step (using 2x Fast Universal PCR Master Mix, no AmpErase ${ }^{\mathrm{TM}}$ UNG and 250ng cDNA template per reaction) qRT-PCR was completed using TaqMan assays (Thermo Fisher Scientific) that detect all 6 FGF13 transcript variants (Assay ID: Hs00182807_m1), variants 2, 3 and 5 (Hs01107046_m1), variant 1 (Hs01113661_m1), or variant 6 (Hs01107039_m1). RPL37A (Hs01102345_m1) was used 
for internal control. Two-step qRT-PCR was conducted using 2x Fast SYBR ${ }^{\mathrm{TM}}$ Green Master Mix (250ng cDNA template per reaction) and a pair of oligonucleotide primers $(1 \mu \mathrm{M}$ each, Integrated DNA Technologies, Singapore) for the following genes: FGF13v4, F 5'-GCGGTGGGGAAAAGCGGATTC , R 5'-AAGCTGAGGCTCCTTAGAAGC; sXBP1, F 5'-TGCTGAGTCCGCAGCAGGTG, $\mathrm{R} \quad$ 5'GCTGGCAGGCTCTGGGGAAG; NaV1.5(SCN5A)adult, F 5'-CATCCTCACCAACTGCGTGT, R 5'ACATTGCCCAGGTCCACAAA; NaV1.5(SCN5A)embryonic, F 5'-CATCCTCACCAACTGCGTGT, R 5'-CCTAGTTTTTCTGATACA; NaV1.6(SCN8A), F 5'-GgGATCCATGGAACTGGTTAGATTT, R 5'GCTCGgAGAACCCTGAATGTT; NaV1.7(SCN9A) F 5'-TATGACCATGAATAACCCGC, R $5^{\prime}-$

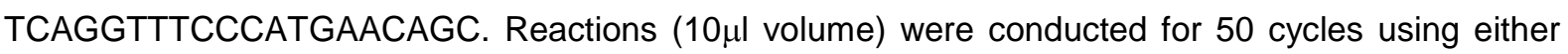
Step One Plus or ViiA 7 real time PCR instruments (Thermo Fisher Scientific).

\section{Analysis of human breast cancer specimens}

Fresh-frozen human breast cancer and adjacent uninvolved normal breast were obtained from the Co-operative Human Tissue Network (CHTN) at the Hospital of the University of Pennsylvania or from Massachusetts General Hospital in accordance with the relevant Institutional Review Board (IRB) standards and guidelines. ${ }^{29-31}$ Clinical variables were gleaned from de-identified pathology reports. Total RNA was isolated from frozen tissue as described previously. ${ }^{29}$ One-step TaqMan qRT-PCR was used to quantify total FGF13, FGF13v2v3v5, FGF13v1 and FGF13v6 mRNA levels whereas twostep SYBR green qRT-PCR was used to quantify FGF13v4 mRNA levels in breast specimens as described above.

\section{Monitoring of tumour growth and metastasis in vivo}

NOD.Cg-Prkdcscid/l2rgtmIWil/SzJ (NSG) immuno-deficient mice (obtained from Walter and Eliza Hall Institute of Medical Research, Parkville, Vic) were maintained in a specific pathogen free environment and fed ad libitum. All procedures involving mice were conducted at the Peter MacCallum Cancer Centre and conformed to National Health and Medical Research Council animal ethics guidelines and were approved by the Animal Experimentation and Ethics Committee (AEEC) of the Peter MacCallum

This article is protected by copyright. All rights reserved. 
Cancer Centre. Mammary tumours were established orthotopically in the right-side inguinal mammary gland of 6-8 week old female mice, and then surgically resected as described previously. ${ }^{9,}{ }^{28}$ Briefly, viable tumour cells resuspended in PBS were mixed with 10-30\% Cultrex (Trevigen) and inoculated $\left(1 \times 10^{6}\right.$ cells $)$ into the right-side inguinal mammary gland of female mice with subsequent surgical resection at a size of $200-400 \mathrm{~mm}^{3}$. Tumour growth and metastasis were also monitored by in vivo bioluminescence imaging (BLI) using intraperitoneal injection of D-luciferin substrate (VivoGlo, Promega) and a Xenogen Lumina II in vivo imaging system (Caliper Life Sciences, Perkin Elmer, Hopkinton, MA, USA), as described previously. ${ }^{22}$ Whole secondary organs were imaged for GFPexpressing metastatic lesions using an Olympus SZX12 fluorescent dissecting stereomicroscope (Olympus, Notting Hill Vic, Australia) and a SPOT digital camera and software (Diagnostic Instruments, Inc. Sterling Heights, MI, USA).

\section{Genomic analysis of metastatic burden}

Mouse lungs and livers (whole organs minus one large lobe from each liver and lung, which was taken for histology) and whole spleen were dissected from mice and genomic DNA isolated following homogenization (PowerLyzer 24, Qiagen) and overnight agitation $\left(55^{\circ} \mathrm{C}\right)$ in genomic digestion buffer. Metastatic burden was quantified using multiplexed TaqMan quantitative real-time PCR (qPCR) comprising PCR reactions specific for human gDNA (hVimentin: F 5'AGAGAACTTTGCCGTTGAAGCT $(1 \mu \mathrm{M})$, R 5'-GAAGGTGACGAGCCATTTCC $(1 \mu \mathrm{M})$, TaqMan probe 5'-6FAM-CCTGCAGGATGAGATTCAGAATATGG-TAMRA 3' $(1 \mu \mathrm{M})$ ) and mouse gDNA (mVimentin: F 5'-AGCTGCTAACTACCAGgACACTATTG $(1 \mu \mathrm{M}), \quad \mathrm{R}$ 5'-CGAAGgtGACGAGCCATCTC $(1 \mu \mathrm{M})$, TaqMan probe 5'-VIC-CCTTCATGTTTTGGATCTCATCCTGCAGG-TAMRA 3' $(1 \mu \mathrm{M})$ ), as described previously. ${ }^{32}$

\section{Histology and immunohistochemistry}

This article is protected by copyright. All rights reserved. 
Tissues were fixed overnight using $10 \%$ neutral buffered formalin and then sectioned for immunohistochemistry $(4 \mu \mathrm{M})$. Mouse monoclonal (AE1/AE3) anti-pan cytokeratin (DAKO, Agilent Technologies, Mulgrave, Vic, Australia) was used to detect human metastatic lesions in mice. Slides were scanned using an Aperio ScanScope and images generated with ImageScope software (Leica Microsystems, Macquarie Park, NSW, Australia).

\section{Data availability}

Relevant data can be made available upon reasonable request.

This article is protected by copyright. All rights reserved. 


\section{RESULTS}

\section{The fibroblast growth factor homologous factor (FHF) gene FGF13 is upregulated in highly metastatic MDA-MB-231 cells}

We recently compared the phenotypes and tumour cell gene expression profiles of four isogenic MDA-MB-231 populations with either no (231_ATCC), an intermediate (231_LNA, 231_LM2), or a high (231_HM.LNm5) ability to metastasize spontaneously from mammary gland to distant organs in immunodeficient mice. ${ }^{9}$ Interrogation of the gene expression profiles (NCBI Accession Number GSE101745) obtained from tumour cells isolated from primary tumour xenografts and subsequent validation by $\mathrm{qRT}-\mathrm{PCR}$ revealed upregulation of FGF13 in each of the three metastatic models versus the non-metastatic 231_ATCC line (Table 1, Figure 1Ai), suggesting a potential role in metastasis.

The FGF13 gene is located on human chromosome Xq26 and can produce six transcript variants encoding five unique protein isoforms, differing only in their $\mathrm{N}$-terminal sequences (Figure S1A). The different isoforms are a result of alternative splicing of $5^{\prime}$ exons and alternative promoter usage (Figure S1B). FGF13 showed a gradient of expression that was in line with the order of metastatic competency, such that 231_ATCC < 231_LNA < 231_LM2 < 231_HM.LNm5 (Table 1). FGF13 expression was especially prominent in 231_HM.LNm5 tumour cells, which displayed over one thousand fold higher levels than in 231_ATCC, as measured by a qRT-PCR reaction that detected all six variants (Figure 1Ai). FGF13 mRNA was also high in cultured 231_HM.LNm5 cells grown in 2D or 3D conditions in vitro (Figure 1B), thereby suggesting a cell intrinsic mechanism of upregulation that does not require the presence of the tumour microenvironment. Similar results were obtained when a qRT-PCR reaction that detected only variants 2,3 and 5 (designated v2v3v5, collectively encoding protein isoforms 2 and 3, Figure S1) was used (data not shown). qRT-PCR analysis of a panel of 22 breast cancer cell lines including 9 TNBC lines (Figure 1C), revealed higher average FGF13 expression in luminal (ER+) and HER2+ lines than in TNBC lines. A similar enrichment in ER+ and HER2+ cell lines was found for FGF13v2v3v5 (Figure S3A). However, analysis of a published microarray dataset that used a largely non overlapping panel of TNBC lines 
demonstrated that a subset of TNBC cell lines (CAL148, HCC1500, MX1) are high for FGF13 expression (Figure S2) ${ }^{33}$

Munoz-Sanjuan et al., reported that certain ectopically-expressed isoforms of FGF13 localized to the nucleus and that protein isoform 1 (encoded by FGF13v1 transcript and also referred to as isoform ' $\mathrm{A}$ ' or isoform ' $\mathrm{S}$ ' in the literature) accumulated in the nucleolus. ${ }^{11}$ Exogenous FGF13 isoform 1 (FGF13i1) was shown recently to localize to the nucleolus in U2OS osteosarcoma cells, where it interacted with key nucleolar proteins such as nucleophosmin/B23 and nucleolin, in addition to partnering with several ribosomal proteins. ${ }^{19}$ Hence, endogenous FGF13v1 expression and FGF13i1 protein levels were evaluated in breast cancer xenografts and cell lines using qRT-PCR and immunofluorescence, respectively. FGF13v1 expression was detectable in primary tumour cells from all MDA-MB-231 variants (Figure 1Aii), however, in contrast to total FGF13 and FGF13v2v3v5 transcripts, FGF13v1 levels were not substantially upregulated in the metastatic lines (Figure 1Aii). FGF13v1 expression in breast cancer cell lines mirrored that of total FGF13 (Figure S3B). The distribution of endogenous FGF13i1 in MDA-MB-231HM cells was somewhat heterogeneous, although staining was observed at the cell periphery and punctate staining was seen in the perinuclear region (Figure S4A), in agreement with literature reports. ${ }^{10}$ Staining was particularly intense in the large nucleoli that are characteristic of cancer cells. Endogenous FGF13i1 was also detected in nucleoli of HER2+ (MDA-MB-361) and ER+ luminal (MDA-MB-175) breast cancer cells (Figure S4B). FGF13i1 exquisitely co-localised with its reported binding partner nucleophosmin/B23 in the outer granular region of nucleoli where nascent ribosome assembly occurs. ${ }^{34}$ This colocalisation was independent of serum availability in MDA-MB-231HM (Figure S4Bi-ii). FGF13i1 was also diffusely distributed throughout the nucleoplasm, however, unlike nucleophosmin/B23, cytoplasmic and perinuclear FGF13i1 was also observed (Figure S4).

One well documented function of FHF proteins pertains to the regulation of voltage-gated sodium channel (VGSC) localization and function in excitable cells such as neurons and cardiomyocytes through binding to the C-terminal intracellular domain of the pore-forming alpha subunits. ${ }^{10,35,36}$ VGSC expression in cancer has also been studied, with three of the nine alpha 
subunits reported to be ectopically expressed by breast cancer cells. ${ }^{37,}{ }^{38} \mathrm{Na}(\mathrm{V}) 1.5$ (SCN5A) encodes the main sodium channel in cardiomyocytes, whereas the closely-related $\mathrm{Na}(\mathrm{V}) 1.6(\mathrm{SCN} 8 \mathrm{~A})$ and $\mathrm{Na}(\mathrm{V}) 1.7$ (SCN9A) channels are expressed in dorsal root ganglia of spinal cord neurons ${ }^{39}$. Neither the embryonic nor adult isoforms of $\mathrm{Na}(\mathrm{V}) 1.5$ were detectable in MDA-MB-231-derived tumour cells and breast cancer cell lines by qRT-PCR (data not shown). $\mathrm{Na}(\mathrm{V}) 1.6$ and $\mathrm{Na}(\mathrm{V}) 1.7$ mRNAs were expressed at a low level in tumour cells from MDA-MB-231-derived xenografts (data not shown), with $\mathrm{Na}(\mathrm{V}) 1.7$ exhibiting slight upregulation in metastatic 231_LNA and 231_HM.LNm5 lines in vivo (Table 1) and in vitro (Figure S5A). $\mathrm{Na}(\mathrm{V}) 1.7$ mRNA levels were higher in TNBC cell lines than in ER+ or HER2+ lines (Figure S5B), a pattern that was the inverse of that seen for FGF13 (Figure 1C).

\section{Expression of FGF13 in human breast cancer}

Expression of FGF13 transcript variants was next evaluated in human breast cancer specimens and adjacent normal breast tissue and tested for association with commonly ascertained clinical variables. Matched primary invasive ductal adenocarcinoma and adjacent uninvolved mammary gland specimens were analysed for total FGF13 mRNA expression by qRT-PCR (Figure S6). While some individual tumours showed enhanced or diminished FGF13 levels relative to normal (Figure S6Ai), no difference in average FGF13 levels were found between breast tumours and normal breast (Figure S6Aii). Similar results were obtained for FGF13v2v3v5 (Figure S6B) and FGF13v4 (which encodes isoform 4) (Figure S6D). However, FGF13v1 expression was significantly downregulated in breast tumours compared with normal breast (Figure S6C). No associations were found between primary tumour expression of total FGF13, FGF13v2v3v5, FGF13v1 or FGF13v4 and presence or absence of oestrogen receptor (ER), progesterone receptor (PR), HER2 receptor or with lymph node metastasis (Table S1), with the notable exception of FGF13v1, levels of which were significantly higher in primary tumours that had disseminated to the lymph node. In addition, no associations were found between expression of FGF13 transcript variants and tumour grade or tumour subtype (Table S1).

We next investigated whether FGF13 activity in primary breast tumours was associated with patient survival in a meta-analysis of several data sets that had extensive associated clinical 
annotation. ${ }^{40}$ When all subtypes of ductal adenocarcinoma were considered in aggregate (Figure 2A2B), higher levels of total FGF13 mRNA were significantly associated with both poorer relapse free survival (R.F.S., H.R. $=1.28, P=9.5 \mathrm{E}-06, \mathrm{n}=3951$ ) and overall survival (O.S., H.R. $=1.36, P=4.9 \mathrm{E}-$ $03, \mathrm{n}=1402)$. Interestingly, subset analyses revealed an association between FGF13 expression and worse prognosis in both luminal A (Figure 2C, H.R. $=1.20, P=3.3 \mathrm{E}-02, \mathrm{n}=1933$ ) and basal-like molecular subtypes (Figure 2F, H.R. $=1.35, P=0.019, \mathrm{n}=618$ ), the latter of which mainly comprises ER negative TNBCs. ${ }^{41}$ FGF13 also showed a trend toward association with worse outcome in luminal B neoplasms (Figure 2D, $P=0.072$ ), but was not linked to outcome in the HER2+ subtype (Figure 2E, $P=0.67)$. Finally, total FGF13 expression and its relationship to patient prognosis was examined in different breast cancer molecular subtypes stratified for p53 mutation status (Figure S7). The majority of luminal A tumours are ER+ and wild-type for p53 and have a relatively good prognosis. ${ }^{42}$ FGF13 expression was strikingly prognostic in this subset (R.F.S. H.R. $=2.64, P=1.7 \mathrm{E}-03, \mathrm{n}=164$ ) (Figure S7C). This strong association with poor outcome was notably absent in luminal A/p53 mutant tumours and luminal B cancers of either p53 genotype (Figure S7A).

Depletion of FGF13 in MDA-MB-231HM cells produces opposite effects on colony forming ability and cell motility

Due to the upregulation of FGF13 expression in highly metastatic MDA-MB-231HM cells and its association with poor survival in breast cancer patients', a functional assessment of FGF13 was conducted by generating MDA-MB-231HM, MDA-MB-361 and MCF-7 breast cancer lines with stable FGF13 knockdown. Unlike MDA-MB-231HM, MDA-MB-361 is a well-differentiated cell line derived from a brain metastasis that expresses both ER and HER2. ${ }^{33,43,44}$ MCF-7 is an ER+ / HER2- luminal cell line. ${ }^{33,}{ }^{44}$ Firefly luciferase-expressing populations of the three cell lines were generated and designated 231HMneoLUC, 361scidneoLUC and MCF7luc2cherry (see Materials and Methods). Three stable FGF13-specific shRNA transfectants were generated for each cell line, with each construct able to target all FGF13 transcript variants (Figure S8-S9). The two shRNA constructs that produced the best knockdown of total FGF13 mRNA levels in each of the cell lines (shFGF13_1 and

This article is protected by copyright. All rights reserved. 
shFGF13_3) were selected for further evaluation (Figure S9A). The extent of reduction of FGF13 mRNA levels was in the range of $\sim 70-90 \%$ for each FGF13 transcript variant or set of variants analysed in transfected 231HMneoLUC cells with shFGF13_1 being more potent than ShFGF13_3 in each case (Figure S9Ai-3Di). In 361scidneoLUC (Figure S9Aii-3Dii) and MCF7luc2cherry (Figure S9Aiii-3Diii), shFGF13_3 was the most effective shRNA. FGF13v6 mRNA was not detected in any cell line (data not shown). Recently, transient depletion of FGF13 in lung cancer cells was reported to induce increased rates of translation and associated proteostatic stress, ${ }^{19}$ which included an unfolded protein response (UPR). These downstream effects were attributed to loss of nucleolar FGF13i1. Therefore, we examined mRNA levels of spliced x-box binding protein-1 (sXBP1), upregulation of which is a marker for the UPR. ${ }^{19}, 45$ SXBP1 levels were paradoxically downregulated in the 231HMneoLUC transfectants harbouring significant FGF13v1 and total FGF13 mRNA knockdown (Figure S9E). However, in MCF7luc2cherry_ShFGF13_3 cells, which showed reduced FGF13v1 expression, sXBP1 mRNA levels were elevated 1.61 fold (Figure S9Eiii).

FGF13 depletion had a negligible effect on cell proliferation in 3D culture in the 231HMneoLUC (Figure 3Ai) and 361scidneoLUC lines (data not shown). However, knockdown of FGF13 significantly reduced 3D proliferation of MCF7luc2cherry_FGF13_3 cells compared with control cells (Figure 3Aii). In contrast to effects on proliferation, reduced FGF13 levels severely attenuated the ability of $231 \mathrm{HMneoLUC}$ cells to form viable colonies from a small number of cells in vitro (Figure 3Bi-3Bii). Indeed, in the knockdown line with lowest FGF13 mRNA expression (shFGF13_1), colony forming ability was reduced to almost zero (Figure 3Bi-3Bii). Colony forming ability was unchanged in 361scidneoLUC and MCF7luc2cherry cell lines with FGF13 knockdown compared with corresponding control lines (data not shown).

There is recent renewed interest in finding biomarkers that are associated with sensitivity or resistance of TNBCs to chemotherapeutic regimens. ${ }^{46,47} \mathrm{~A}$ meta-analysis of several data sets showed that FGF13 expression was linked to worse prognosis in patients receiving any chemotherapeutic regimen (Figure S10A), and that the association was enhanced in individuals who received chemotherapy in the adjuvant setting (Figure S10B, R.F.S. H.R. $=1.47, P=1.3 \mathrm{E}-02, \mathrm{n}=594$ ). ${ }^{40}$ 
Okada et al., showed recently that FGF13 expression was markedly upregulated in HeLa cervical cancer cells selected for resistance to the DNA damaging agent cisplatin, and ectopic expression FGF13 in parental HeLa cells resulted in cisplatin resistance. ${ }^{14}$ Therefore, we tested whether direct suppression of FGF13 levels in breast cancer cells could affect cisplatin-induced cell death. Control and FGF13 knockdown 231HMneoLUC cells were incubated with cisplatin and half maximal inhibitory concentration $\left(\mathrm{IC}_{50}\right.$ ) values determined (Figure 3C). FGF13 knockdown significantly reduced cisplatin $I_{50}$ values in $231 \mathrm{HMneoLUC}$ in a manner that was proportional to the magnitude of FGF13 suppression (Figure 3Cii, Figure S9Ai). To ascertain whether FGF13 could be involved in the resistance of patient tumours to cisplatin, data were interrogated from a clinical trial of neo-adjuvant cisplatin in TNBC patients. ${ }^{46}$ Baseline tumour FGF13 mRNA levels were recorded in treatment-naive patients and then assigned a response score based on extent of the pathologic response to cisplatin. ${ }^{48}$ However, no significant difference in FGF13 mRNA levels was observed in patients with either a good (score of 3-5) or poor (0-2) response (Figure S10C).

The effect of FGF13 knockdown on the in vitro motility of 231HMneoLUC cells was then evaluated. Transwell assays demonstrated that FGF13 depletion significantly enhanced both directional migration (Figure 3D) and invasion through basement membrane (Figure 3E), when serum was used as the chemoattractant. The magnitude of the effect was inversely proportional to the extent of FGF13 knockdown in both types of motility assay (Figure 3C-3D). The well-differentiated MDA-MB-361 and MCF-7 cells are not motile and hence were not tested in these assays.

\section{Knockdown of FGF13 reduces spontaneous metastasis to distant organs without affecting primary tumour growth}

MDA-MB-231HM cells spontaneously metastasize from the mammary gland to distant organs in immunodeficient mice. ${ }^{9,} 23-25$ The non-motile MDA-MB-361 cell line is tumourigenic but does not metastasize. Thus we evaluated the effects of FGF13 suppression on primary tumour formation and growth using the 231HMneoLUC and 361scidneoLUC models. Spontaneous metastasis was also investigated in mice bearing $231 \mathrm{HMneoLUC}$ tumours following primary tumour resection. Both of the 
FGF13-depleted 231HMneoLUC lines were tumourigenic, and no significant difference in primary tumour growth rates between knockdown and control lines was recorded (Figure S11A). 361scidneoLUC-derived tumours grew more slowly though again, no difference in growth rate was observed between the groups (Figure S11B-11D). Primary tumours were resected at the same size (Figure S12) and analysis of FGF13 expression in 231HMneoLUC (Figure S11Ei) and 361scidneoLUC (Figure S11Eii) xenografts demonstrated that reduced FGF13 levels were maintained in the FGF13 knockdown lines throughout the primary tumour growth phase.

As anticipated, metastasis was not found in mice observed for up to 3 months following resection of 361scidneoLUC mammary tumours (data not shown). However, significantly less metastasis to distant organs was detected by BLI in 231HMneoLUC_shFGF13_1 tumour bearing mice compared to the control shNC line 22 days after resection (Figure 4A-4B). Ex vivo fluorescence microscopy and genomic qPCR demonstrated robust spontaneous metastasis of control 231HMneoLUC cells to lung, liver and spleen (Figure 4C-4D, Figure S13). Significantly lower tumour burden was detected in both the lungs and livers of mice inoculated with 231HMneoLUC_shFGF13_1 cells compared to controls (Figure 4C-4D, Figure S13A-S13B). A trend toward lower metastatic burden in lung and liver was also found for 231HMneoLUC_shFGF13_3 tumours by genomic qPCR (Figure 4Di-4Dii). FGF13 depletion did not affect spontaneous metastasis to spleen (Figure 4Diii, Figure S13C). These findings were supported by pan-cytokeratin staining of lung (Figure 4E), and liver (Figure 4F) sections for the presence of metastatic deposits. The very low metastatic burden in the lungs of 231HMneoLUC_shFGF13_1 bearing mice, which was observed using multiple approaches, raised the possibility that a certain threshold of FGF13 expression might be required for homing of disseminated tumour cells to lung. However, careful inspection of serial lung sections revealed the presence of small pan-cytokeratin positive micrometastases formed by 231HMneoLUC_shFGF13_1 cells (Figure S14). 


\section{DISCUSSION}

FGF13 was identified as a gene with a potential role in breast cancer metastasis, as its expression was upregulated in each of the three metastatic TNBC models compared to the parental MDA-MB231 line, with mRNA levels exceeding 1,000-fold elevation in highly metastatic MDA-MB-231HMderived cells. On average, there was no difference in total FGF13 mRNA levels between primary breast ductal adenocarcinomas and adjacent normal mammary gland and despite higher expression in ER+ and HER2+ breast cancer cell lines compared to TNBC lines (Figure 1C), no differences in FGF13 expression were found among the different breast cancer subtypes in whole tumour analyses, nor were total FGF13 transcript levels associated with any of the standard clinical variables (Table S1A). However, FGF13 expression levels were significantly associated with patient survival. Specifically, high FGF13 activity was associated with worse relapse-free survival in breast cancer patients with either basal-like or luminal A tumour subtypes (Figure 2). These findings are similar to recent data in prostate cancer, where cytoplasmic FGF13 protein levels were positively associated with reduced time to biochemical relapse after radical prostatectomy, but not with other clinicopathologic variables. ${ }^{13}$

Despite high expression of FGF13 in metastatic MDA-MB-231HM cells, stable knockdown of FGF13 unexpectedly promoted both cell migration and invasion in vitro. The FGF13 binding partners $\mathrm{Na}(\mathrm{V}) 1.5, \mathrm{Na}(\mathrm{V}) 1.6$ and $\mathrm{Na}(\mathrm{V}) 1.7$ have each been shown to increase cancer cell invasion through a mechanism involving proton efflux by the $\mathrm{Na}^{+} / \mathrm{H}^{+}$exchanger NHE1 and subsequent activation of extracellular cysteine cathepsins. ${ }^{37}$ Consistent with this, $\mathrm{Na}(\mathrm{V}) 1.7$ (SCN9A) was upregulated in metastatic MDA-MB-231HM cells compared to parental cells, and TNBC cells possessing invasive ability had higher average $\mathrm{Na}(\mathrm{V}) 1.7$ levels than the less motile ER+ and HER2+ cell lines (Figure S5B). A fraction of endogenous FGF13i1 was observed at the plasma membrane in MDA-MB-231HM cells thereby raising the possibility that binding of FGF13 isoforms to the $\mathrm{Na}(\mathrm{V}) 1.7 \mathrm{C}$ terminus attenuates the ability of $\mathrm{Na}(\mathrm{V}) 1.7$ to promote cell migration and invasion, although additional experimentation is required to prove this. In contrast to the current study, it was recently shown that 
knockdown of FGF13 in J3T-2 human glioma cells reduced in vitro migration as well as invasion of intra-cranial J3T-2 cell xenografts. ${ }^{17}$ Promotion of cell motility by FGF13 was postulated to occur through stabilisation of microtubules.

FGF13 knockdown had no significant effect on the growth of MDA-MB-231HM cells or MDAMB-361 cells in vitro or in vivo. However, reduction of FGF13 in MCF7 cells suppressed growth in 3D culture and this was associated with an increase in expression of SXBP1 (Figure S9Eiii), raising the possibility that FGF13i1 depletion caused an UPR leading to attenuation of cell proliferation.

Despite enhancing cell motility, FGF13 depletion markedly reduced both MDA-MB-231HM colony forming ability and spontaneous metastasis to lung and liver in vivo. In fact, reducing FGF13 levels to approximately $10 \%$ of that found in controls (in the case of 231HMneoLUC_shFGF13_1 cells) almost completely blocked both colony formation and metastasis, although the effects on metastasis were not due to an inability of the FGF13-depleted cells to home to lung as demonstrated by the presence of numerous microscopic lesions in this organ. Increased cell motility in vitro does not always translate to an increased metastasis in vivo as the process of metastasis involves activities in addition to the ability to move and invade basement membrane. Cells need to be able to survive in the circulation, extravasate, and proliferate into macrometastatic lesions. For example, we recently showed that highly metastatic MDA-MB-231_HM cells display less directional in vitro motility than non-metastatic parental MDA-MB-231 cells. ${ }^{9}$ These data indicate a requirement for FGF13 for the successful expansion of initiated micrometastatic deposits in lung and the failure of FGF13 suppressed cells to form colonies in vitro when seeded at low density supports this hypothesis. The inability of FGF13 depleted MDA-MB-231HM cells to establish colonies once seeded is unlikely to involve induction of an UPR, as SXBP1 was not induced in either 231HMneoLUC line with FGF13 knockdown.

The FGF13 protein isoform, or combination of isoforms that are necessary for promoting the expansion of small cell clusters of TNBC cells is an important question, since this function may underlie the association of FGF13 with worse relapse free survival. The data indicate that the two best characterized isoforms ${ }^{49}$ FGF13i1 (encoded by FGF13v1) and FGF13i5 (encoded by FGF13v6) are 
not involved. FGF13v6 mRNA was not detected in either MDA-MB-231HM, MDA-MB-361 cells, nor in normal or malignant mammary gland. Despite demonstrating expression of endogenous FGF13i1 in the nucleoli of ER+, HER2+ and TNBC breast cancer cells for the first time (Figure S4), FGF13i1 can also be eliminated for the following reasons. 1. Endogenous FGF13v1 expression was not appreciably upregulated in highly metastatic 231_HM.LNm5 cells relative to the other 3 isogenic lines. 2. Unlike the finding in the MCF7 line, the suppressed level of FGF13v1 in FGF13-depleted 231_HM.LNm5 cells was not able to produce the expected UPR as determined by analysis of SXBP-1 levels (compare Figure S9Ci and iii with Figure S9Ei and iii). ${ }^{19}$ 3. Expression of FGF13v1 was significantly downregulated in primary breast tumours compared to normal mammary gland (Figure S6C), and 4. Our RNA-Seq data showed that MDA-MB-231HM-derived tumour cells display upregulation of multiple gene sets involved in ribosome biogenesis and rRNA metabolism concomitant with increased FGF13 expression. ${ }^{9}$ Based on recent data from Bublik et al., increased FGF13i1 expression would be expected to suppress ribosome biogenesis and rRNA metabolism. ${ }^{19}$ In addition, cytoplasmic FGF13 staining was associated with time to relapse in prostate cancer patients while nuclear FGF13 positivity was not, suggesting that the nucleolar FGF13i1 is not driving the association of FGF13 with prostate cancer outcome. ${ }^{13}$ This does not, however, preclude a role for FGF13i1 in other aspects of breast cancer biology, especially in the ER+ luminal subtypes, as ER+ luminal cell lines expressed the highest levels of FGF13v1 (Figure S3B), and FGF13 suppression in ER+ MCF7 cells reduced cell growth and potentially activated an UPR.

Together, the data indicate that the less well characterised protein isoforms FGF13i2 and/or FGF13i3, and potentially also FGF13i4 are functionally involved in promoting the metastasis of TNBC cells to secondary sites. These FGF13 isoforms may have potential utility as biomarkers to identify a TNBC patient cohort who have the poorest prognosis.

This article is protected by copyright. All rights reserved. 


\section{CONFLICT OF INTEREST STATEMENT}

All authors declare no conflicts of interest.

\section{ACKNOWLEDGEMENTS}

This study was supported by a Cass Foundation of Victoria (Australia) Grant \#SM/14/5567 (to CNJ), and National Health and Medical Research Council (Australia) project grants APP1128250 and APP1042848 (to THB), and APP1050384 and APP1020280 (to RLA). We would like to thank the Animal Core Facility, Flow Cytometry Core Facility, and Centre for Advanced Histology and Microscopy (CAHM) at the Peter MacCallum Cancer Centre for services provided. We would also like to thank the Victorian Centre for Functional Genomics (VCFG) for the provision of pGIPZ lentiviral vectors, Sue Sturrock and Stephen Fox (Anatomical Pathology, Peter Mac) for immunohistochemistry services, Elaine Sanij and Richard Pearson (Peter Mac) for nucleophosmin/B23 and fibrillarin antibodies. Joan Massague (Memorial Sloan Kettering Cancer Centre) provided the MDA-MB231_LM2 cell line and ZM Shao and ZL Ou (Breast Cancer Institute, Fudan University, Shanghai) provided the MDA-MB-231HM cell line. We thank Judy Doherty (Peter Mac) for generation of the 231_LNA cell line and David Baloyan (ONJCRI) for assistance with flow cytometry and cell cycle analysis.

This article is protected by copyright. All rights reserved. 


\section{REFERENCES}

1. Eckhardt BL, Francis PA, Parker BS, Anderson RL. Strategies for the discovery and development of therapies for metastatic breast cancer. Nat Rev Drug Discov 2012;11:479-97.

2. Liedtke C, Mazouni C, Hess KR, Andre F, Tordai A, Mejia JA, Symmans WF, GonzalezAngulo AM, Hennessy B, Green M, Cristofanilli M, Hortobagyi GN, et al. Response to neoadjuvant therapy and long-term survival in patients with triple-negative breast cancer. J. Clin. Oncol. 2008;26:1275-81.

3. Carey LA, Perou CM, Livasy CA, Dressler LG, Cowan D, Conway K, Karaca G, Troester MA, Tse CK, Edmiston S, Deming SL, Geradts J, et al. Race, breast cancer subtypes, and survival in the Carolina Breast Cancer Study. JAMA 2006;295:2492-502.

4. Lehmann BD, Bauer JA, Chen X, Sanders ME, Chakravarthy AB, Shyr Y, Pietenpol JA. Identification of human triple-negative breast cancer subtypes and preclinical models for selection of targeted therapies. J. Clin. Invest. 2011;121:2750-67.

5. Lehmann BD, Jovanovic B, Chen X, Estrada MV, Johnson KN, Shyr Y, Moses HL, Sanders ME, Pietenpol JA. Refinement of Triple-Negative Breast Cancer Molecular Subtypes: Implications for Neoadjuvant Chemotherapy Selection. PLoS One 2016;11:e0157368.

6. Turner NC, Reis-Filho JS. Tackling the diversity of triple-negative breast cancer. Clin. Cancer Res. 2013;19:6380-8.

7. Hennessy BT, Gonzalez-Angulo AM, Stemke-Hale K, Gilcrease MZ, Krishnamurthy S, Lee JS, Fridlyand J, Sahin A, Agarwal R, Joy C, Liu W, Stivers D, et al. Characterization of a naturally occurring breast cancer subset enriched in epithelial-to-mesenchymal transition and stem cell characteristics. Cancer Res. 2009;69:4116-24.

8. Prat A, Parker JS, Karginova O, Fan C, Livasy C, Herschkowitz JI, He X, Perou CM. Phenotypic and molecular characterization of the claudin-low intrinsic subtype of breast cancer. Breast Cancer Res. 2010;12:R68.

9. Johnstone CN, Pattison AD, Gorringe KL, Harrison PF, Powell DR, Lock P, Baloyan D, Ernst M, Stewart AG, Beilharz TH, Anderson RL. Functional and genomic characterisation of a xenograft model system for the study of metastasis in triple-negative breast cancer. Dis. Model. Mech. 2018;11.

10. Goldfarb M. Fibroblast growth factor homologous factors: evolution, structure, and function. Cytokine Growth Factor Rev. 2005;16:215-20.

11. Munoz-Sanjuan I, Smallwood PM, Nathans J. Isoform diversity among fibroblast growth factor homologous factors is generated by alternative promoter usage and differential splicing. J. Biol. Chem. 2000;275:2589-97.

12. Greene JM, Li YL, Yourey PA, Gruber J, Carter KC, Shell BK, Dillon PA, Florence C, Duan DR, Blunt A, Ornitz DM, Ruben SM, et al. Identification and characterization of a novel member of the fibroblast growth factor family. Eur. J. Neurosci. 1998;10:1911-25.

13. Yu L, Toriseva M, Tuomala M, Seikkula H, Elo T, Tuomela J, Kallajoki M, Mirtti T, Taimen P, Bostrom PJ, Alanen K, Nurmi M, et al. Increased expression of fibroblast growth factor 13 in prostate cancer is associated with shortened time to biochemical recurrence after radical prostatectomy. Int. J. Cancer 2016;139:140-52. 
14. Okada T, Murata K, Hirose R, Matsuda C, Komatsu T, Ikekita M, Nakawatari M, Nakayama F, Wakatsuki M, Ohno T, Kato S, Imai T, et al. Upregulated expression of FGF13/FHF2 mediates resistance to platinum drugs in cervical cancer cells. Sci. Rep. 2013;3:2899.

15. Gutierrez NC, Lopez-Perez R, Hernandez JM, Isidro I, Gonzalez B, Delgado M, Ferminan E, Garcia JL, Vazquez L, Gonzalez M, San Miguel JF. Gene expression profile reveals deregulation of genes with relevant functions in the different subclasses of acute myeloid leukemia. Leukemia 2005;19:402-9.

16. Hoek K, Rimm DL, Williams KR, Zhao H, Ariyan S, Lin A, Kluger HM, Berger AJ, Cheng E, Trombetta ES, $\mathrm{Wu} T$, Niinobe $\mathrm{M}$, et al. Expression profiling reveals novel pathways in the transformation of melanocytes to melanomas. Cancer Res. 2004;64:5270-82.

17. Otani Y, Ichikawa T, Kurozumi K, Inoue S, Ishida J, Oka T, Shimizu T, Tomita Y, Hattori Y, Uneda $\mathrm{A}$, Matsumoto $\mathrm{Y}$, Michiue $\mathrm{H}$, et al. Fibroblast growth factor 13 regulates glioma cell invasion and is important for bevacizumab-induced glioma invasion. Oncogene 2017.

18. Roszik J, Ring KL, Wani KM, Lazar AJ, Yemelyanova AV, Soliman PT, Frumovitz M, Jazaeri AA. Gene Expression Analysis Identifies Novel Targets for Cervical Cancer Therapy. Front. Immunol. 2018;9:2102.

19. Bublik DR, Bursac S, Sheffer M, Orsolic I, Shalit T, Tarcic O, Kotler E, Mouhadeb O, Hoffman Y, Fuchs G, Levin Y, Volarevic S, et al. Regulatory module involving FGF13, miR-504, and p53 regulates ribosomal biogenesis and supports cancer cell survival. Proc. Natl. Acad. Sci. U. S. A. 2017;114:E496-E505.

20. Cailleau R, Mackay B, Young RK, Reeves WJ, Jr. Tissue culture studies on pleural effusions from breast carcinoma patients. Cancer Res. 1974;34:801-9.

21. Minn AJ, Gupta GP, Siegel PM, Bos PD, Shu W, Giri DD, Viale A, Olshen AB, Gerald WL, Massague J. Genes that mediate breast cancer metastasis to lung. Nature 2005;436:518-24.

22. Johnstone CN, Mongroo PS, Rich AS, Schupp M, Bowser MJ, Delemos AS, Tobias JW, Liu $Y$, Hannigan GE, Rustgi AK. Parvin-beta inhibits breast cancer tumorigenicity and promotes CDK9mediated peroxisome proliferator-activated receptor gamma 1 phosphorylation. Mol. Cell. Biol. 2008;28:687-704.

23. Chang XZ, Li DQ, Hou YF, Wu J, Lu JS, Di GH, Jin W, Ou ZL, Shen ZZ, Shao ZM. Identification of the functional role of $A F 1 Q$ in the progression of breast cancer. Breast Cancer Res. Treat. 2008;111:65-78.

24. Chang XZ, Li DQ, Hou YF, Wu J, Lu JS, Di GH, Jin W, Ou ZL, Shen ZZ, Shao ZM. Identification of the functional role of peroxiredoxin 6 in the progression of breast cancer. Breast Cancer Res. 2007;9:R76.

25. Fietz ER, Keenan CR, Lopez-Campos G, Tu Y, Johnstone CN, Harris T, Stewart AG. Glucocorticoid resistance of migration and gene expression in a daughter MDA-MB-231 breast tumour cell line selected for high metastatic potential. Sci. Rep. 2017;7:43774.

26. Rautela J, Baschuk N, Slaney CY, Jayatilleke KM, Xiao K, Bidwell BN, Lucas EC, Hawkins ED, Lock P, Wong CS, Chen W, Anderson RL, et al. Loss of Host Type-I IFN Signaling Accelerates Metastasis and Impairs NK-cell Antitumor Function in Multiple Models of Breast Cancer. Cancer immunology research 2015;3:1207-17.

27. Czekanska EM. Assessment of cell proliferation with resazurin-based fluorescent dye. Methods Mol. Biol. 2011;740:27-32.

28. Johnstone CN, Smith YE, Cao Y, Burrows AD, Cross RS, Ling X, Redvers RP, Doherty JP, Eckhardt BL, Natoli AL, Restall CM, Lucas E, et al. Functional and molecular characterisation of 
EO771.LMB tumours, a new C57BL/6-mouse-derived model of spontaneously metastatic mammary cancer. Dis. Model. Mech. 2015;8:237-51.

29. Mongroo PS, Johnstone CN, Naruszewicz I, Leung-Hagesteijn C, Sung RK, Carnio L, Rustgi AK, Hannigan GE. Beta-parvin inhibits integrin-linked kinase signaling and is downregulated in breast cancer. Oncogene 2004;23:8959-70.

30. Johnstone CN, Castellvi-Bel S, Chang LM, Bessa X, Nakagawa H, Harada H, Sung RK, Pique JM, Castells A, Rustgi AK. ARHGAP8 is a novel member of the RHOGAP family related to ARHGAP1/CDC42GAP/p50RHOGAP: mutation and expression analyses in colorectal and breast cancers. Gene 2004;336:59-71.

31. Johnstone CN, Castellvi-Bel S, Chang LM, Sung RK, Bowser MJ, Pique JM, Castells A, Rustgi AK. PRR5 encodes a conserved proline-rich protein predominant in kidney: analysis of genomic organization, expression, and mutation status in breast and colorectal carcinomas. Genomics 2005;85:338-51.

32. Eckhardt BL, Parker BS, van Laar RK, Restall CM, Natoli AL, Tavaria MD, Stanley KL, Sloan EK, Moseley JM, Anderson RL. Genomic analysis of a spontaneous model of breast cancer metastasis to bone reveals a role for the extracellular matrix. Mol. Cancer Res. 2005;3:1-13.

33. Hoeflich KP, O'Brien C, Boyd Z, Cavet G, Guerrero S, Jung K, Januario T, Savage H, Punnoose E, Truong T, Zhou W, Berry $L$, et al. In vivo antitumor activity of MEK and phosphatidylinositol 3-kinase inhibitors in basal-like breast cancer models. Clin. Cancer Res. 2009;15:4649-64.

34. Maggi LB, Jr., Kuchenruether M, Dadey DY, Schwope RM, Grisendi S, Townsend RR, Pandolfi PP, Weber JD. Nucleophosmin serves as a rate-limiting nuclear export chaperone for the Mammalian ribosome. Mol. Cell. Biol. 2008;28:7050-65.

35. Goldfarb M. Voltage-gated sodium channel-associated proteins and alternative mechanisms of inactivation and block. Cell. Mol. Life Sci. 2012;69:1067-76.

36. Yang L, Dong F, Yang Q, Yang PF, Wu R, Wu QF, Wu D, Li CL, Zhong YQ, Lu YJ, Cheng X, Xu FQ, et al. FGF13 Selectively Regulates Heat Nociception by Interacting with Nav1.7. Neuron 2017;93:806-21 e9.

37. Brackenbury WJ. Voltage-gated sodium channels and metastatic disease. Channels (Austin) 2012;6:352-61.

38. Roger S, Gillet L, Le Guennec JY, Besson P. Voltage-gated sodium channels and cancer: is excitability their primary role? Front. Pharmacol. 2015;6:152.

39. Kruger LC, Isom LL. Voltage-Gated Na+ Channels: Not Just for Conduction. Cold Spring Harb. Perspect. Biol. 2016;8.

40. Gyorffy B, Lanczky A, Eklund AC, Denkert C, Budczies J, Li Q, Szallasi Z. An online survival analysis tool to rapidly assess the effect of 22,277 genes on breast cancer prognosis using microarray data of 1,809 patients. Breast Cancer Res. Treat. 2010;123:725-31.

41. Prat A, Adamo B, Cheang MC, Anders CK, Carey LA, Perou CM. Molecular characterization of basal-like and non-basal-like triple-negative breast cancer. Oncologist 2013;18:123-33.

42. Bertheau P, Lehmann-Che J, Varna M, Dumay A, Poirot B, Porcher R, Turpin E, Plassa LF, de Roquancourt A, Bourstyn E, de Cremoux $P$, Janin A, et al. p53 in breast cancer subtypes and new insights into response to chemotherapy. Breast 2013;22 Suppl 2:S27-9.

43. Cailleau R, Olive $M$, Cruciger QV. Long-term human breast carcinoma cell lines of metastatic origin: preliminary characterization. In Vitro 1978;14:911-5.

This article is protected by copyright. All rights reserved. 
44. Neve RM, Chin K, Fridlyand J, Yeh J, Baehner FL, Fevr T, Clark L, Bayani N, Coppe JP, Tong F, Speed T, Spellman PT, et al. A collection of breast cancer cell lines for the study of functionally distinct cancer subtypes. Cancer Cell 2006;10:515-27.

45. van Schadewijk A, van't Wout EF, Stolk J, Hiemstra PS. A quantitative method for detection of spliced X-box binding protein-1 (XBP1) mRNA as a measure of endoplasmic reticulum (ER) stress. Cell Stress Chaperones 2012;17:275-9.

46. Silver DP, Richardson AL, Eklund AC, Wang ZC, Szallasi Z, Li Q, Juul N, Leong CO, Calogrias D, Buraimoh A, Fatima A, Gelman RS, et al. Efficacy of neoadjuvant Cisplatin in triple-negative breast cancer. J. Clin. Oncol. 2010;28:1145-53.

47. Petrelli F, Coinu A, Borgonovo K, Cabiddu M, Ghilardi M, Lonati V, Barni S. The value of platinum agents as neoadjuvant chemotherapy in triple-negative breast cancers: a systematic review and meta-analysis. Breast Cancer Res. Treat. 2014;144:223-32.

48. Ogston KN, Miller ID, Payne S, Hutcheon AW, Sarkar TK, Smith I, Schofield A, Heys SD. A new histological grading system to assess response of breast cancers to primary chemotherapy: prognostic significance and survival. Breast 2003;12:320-7.

49. Pablo JL, Pitt GS. Fibroblast Growth Factor Homologous Factors: New Roles in Neuronal Health and Disease. Neuroscientist 2016;22:19-25.

\begin{tabular}{|c|c|c|c|c|c|c|c|c|}
\hline $\begin{array}{c}\text { Gene } \\
\text { Symbol }\end{array}$ & \multicolumn{3}{|c|}{ RNA-Seq data } & $\begin{array}{c}\text { Adjusted } P \\
\text { (ANOVA) }\end{array}$ & \multicolumn{3}{c|}{ qRT-PCR } & $P$ (ANOVA) \\
\hline & LNA & LM2 & HM & & LNA & LM2 & HM & \\
\hline $\begin{array}{c}\text { SCN8A } \\
\text { (NaV1.6) }\end{array}$ & nd & nd & nd & - & 0.75 & 1.60 & 1.72 & $3.63 \mathrm{E}-02$ \\
\hline $\begin{array}{c}\text { SCN9A } \\
\text { (NaV1.7) }\end{array}$ & 0.72 & 0.20 & 0.86 & $1.60 \mathrm{E}-03$ & 7.73 & 1.33 & 12.73 & $1.97 \mathrm{E}-04$ \\
\hline FGF13 & $\mathbf{0 . 2 9}$ & $\mathbf{1 . 9 8}$ & $\mathbf{2 9 . 3 9}$ & $\mathbf{1 . 2 7 E - 0 8}$ & $\mathbf{8 . 0 2}$ & $\mathbf{5 3 . 2 7}$ & $\mathbf{1 4 8 2}$ & $\mathbf{7 . 6 2 \mathrm { E } - 0 7}$ \\
\hline
\end{tabular}

\section{Table 1}


Figure and Table legends

Table 1: Differential gene expression among four MDA-MB-231-derived isogenic tumour models. RNA-Seq was conducted using cancer cells isolated from primary mammary tumours established in NSG mice. ${ }^{9}$ Data were generated from the following models. 231_ATCC $(n=2$ tumours), 231_LNA ( $n=6), 231$ LM2 $(n=6), 231$ HM.LNm5 $(n=6)$. Changes in expression of FGF13 and its cognate receptors SCN8A and SCN9A among the four different models were also validated by qRT-PCR using independent isolated tumour cell samples ( $\mathrm{n}=3$ per model). Mean gene expression levels were set to one in 231_ATCC (non metastatic) tumours for both RNA-Seq and qRT-PCR data. Gene expression ratios in the three metastatic tumour models (231_LNA, 231_LM2, 231_HM.LNm5) are shown as is the $P$ value (one-way ANOVA). nd, not detected.

Figure 1: FGF13 expression in MDA-MB-231 breast cancer xenografts and cell lines. A. FGF13 mRNA expression measured by TaqMan qRT-PCR in primary tumour cells isolated from MDA-MB231 xenografts cells. Two tumours ( $A$ and $B$ ) from each of the four models are displayed. Expression in 231_ATCC-A was set to one. Mean +/- S.D. $(n=3)$. i. Total FGF13 mRNA levels (all 6 transcript variants) ii. FGF13 transcript variant $1 .{ }^{\star \star \star} P<0.001$ (one-way ANOVA). n/s. not significant. B. TaqMan qRT-PCR analysis of total FGF13 mRNA expression in 2D and 3D cultures of MDA-MB-231 variants and in MCF10A immortalised mammary epithelial cells. Expression in 231_ATCC (2D) was set to one. Mean +/- S.D. (n=3). ${ }^{* \star *} P<0.001$ (2D, one-way ANOVA; 3D, Students t-test). C. Evaluation of total FGF13 mRNA expression by TaqMan qRT-PCR in a panel of human breast cancer cell lines (2D culture). The breast cancer subtype (ER+, HER2+ or TNBC) is indicated. Expression in MCF10A was set to one. Mean +/- S.D. (n=3). FGF13 mRNA levels were higher in ER+ and HER2+ lines than in TNBC lines.

Figure 2: Kaplan-Meier analysis demonstrating significant association between FGF13 transcript levels in primary breast ductal adenocarcinoma and patient outcome. Samples were

This article is protected by copyright. All rights reserved. 
divided into two groups at the median FGF13 mRNA expression level. The number of patients with high (red) and low (black) FGF13 expression is indicated as is the total number of patients (n) (http://www.kmplot.com/analysis). The follow-up time (months) is indicated on the x-axis. Hazard Ratios (HR), 95\% confidence intervals and logrank $P$ values are also shown. ${ }^{*}, P<0.05 ;{ }^{*}, P<0.01$; ${ }^{* *}, P<0.001$. A, B. Association between FGF13 expression and relapse-free survival (R.F.S.) or overall survival (O.S.), respectively, in all ductal adenocarcinoma subtypes. C-F. Association between FGF13 expression and relapse-free survival (R.F.S.) in the four indicated molecular subtypes of breast ductal adenocarcinoma. The percentage of tumours contributing to each subtype is shown on the right.

Figure 3. In vitro characterization of FGF13-depleted breast cancer cells. A. Cell proliferation in 3D culture was assessed in 231HMneoLUC (i) and MCF7luc2cherry (ii) stable transfectants over 4 days. Mean +/- S.D. (n=4). ${ }^{\star \star}, P<0.01 ;{ }^{\star \star \star}, P<0.001 ;{ }^{* \star \star}$. Student's t-test (shNC v shFGF13_3). B. Effect of FGF13 knock-down on colony formation in MDA-MB-231_HM cells. An equal number of viable GFP-positive FGF13 knock-down or control (shNC) 231HMneoLUC cells was seeded and the number of colonies formed was enumerated after 14d. (i) Representative images of colonies formed (ii) Quantification of colony formation. Mean +/- S.E.M is shown. One-way ANOVA $P<0.0001$. ${ }^{\star \star \star \star}, P$ $<0.0001$ versus control shNC cells. No effect on colony formation was seen when FGF13 was depleted in 361scidneoLUC or MCF7luc2cherry cell lines (data not shown). C. Effect of FGF-13 knock-down on sensitivity of MDA-MB-231HMneoLUC cells to cisplatin. Cells were exposed to 10 different cisplatin concentrations ( $n=6$ per dose) over 4 days. Non-linear regression analysis was used to determine cisplatin $\mathrm{IC}_{50}$ values $(\mu \mathrm{M})$ for each line. (i) Plot of mean surviving fraction +/- S.E.M. versus $\log _{10}$ [concentration]. The surviving fraction at the lowest dose of drug was set to 1.00 . (ii). The cisplatin $\mathrm{IC}_{50}$ values $(\mu \mathrm{M})+/-95 \%$ confidence interval $(\mathrm{Cl})$ are presented graphically. ${ }^{*}, P<0.05$ versus control shNC cells. D. Effect of FGF13 knock-down on MDA-MB-231HMneoLUC cell migration. Transwell migration assays were conducted for $21 \mathrm{~h}$ using $10 \%$ serum as chemoattractant. Representative images of calcein ${ }^{\mathrm{AM}}$-stained migrated cells are shown (x10 magnification). 
i. shNC, ii. ShFGF13_1, iii. shFGF13_3. iv. Quantification of migration assay. Mean number of migrated cells per field +/- S.E.M. $(n=3)$. One-way ANOVA $P=0.0075 .{ }^{*}, P<0.01$; ns, not significant (versus control shNC cells). E. Effect of FGF13 knock-down on MDA-MB-231HMneoLUC cell invasion. Transwell invasion assays were conducted for $24 \mathrm{~h}$ using $10 \%$ serum as chemo-attractant. Representative images of calcein ${ }^{\mathrm{AM}}$-stained invaded cells are shown ( $\mathrm{x} 10$ magnification, scale bars $100 \mu \mathrm{M})$. i. shNC, ii. shFGF13_1, iii. shFGF13_3. iv. Quantification of invasion assay. Mean number of invaded cells per field +/- S.E.M. ( $\mathrm{n}=3$ ). One-way ANOVA $P=0.0128$. ${ }^{*}, P<0.05$; ns, not significant (versus control shNC cells).

Figure 4: Evaluation of metastasis in FGF13 depleted MDA-MB-231_HM cells. A. Mice inoculated with MDA-MB-231HMneoLUC transfectants were analysed for spontaneous metastasis to axillary lymph nodes and thoracic cavity by bioluminescence imaging 22 days after surgical resection of the primary tumour. $\mathrm{n}=6$ per line. The radiance $\left(\mathrm{p} / \mathrm{sec} / \mathrm{cm}^{2} / \mathrm{sr}\right)$ colour scale is shown to the right of the images. i. shNC. ii. ShFGF13_1. iii. shFGF13_3. B. Quantification of bioluminescent signal intensity of distant metastases (corresponding to the cranial and thoracic regions displayed in A) 22 days after primary tumour resection. The adjusted average radiance for each individual is shown. Mean $+/$ - S.E.M. $\mathrm{n}=6$ per group. One-way ANOVA $P=0.289 .{ }^{*}, P=0.031$ (shNC vs. shFGF13_1); ns (shNC vs. ShFGF13_3). C. Representative images of whole mouse livers (GFP fluorescence) demonstrating spontaneous metastasis of MDA-MB-231HMneoLUC transfectants i. shNC. ii. shFGF13_1. iii. shFGF13_3. Magnification (x7). D. Quantification of spontaneous metastasis of MDA-MB-231HMneoLUC-derived primary tumours to distant organs by genomic qPCR analysis.

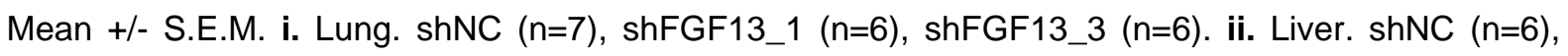

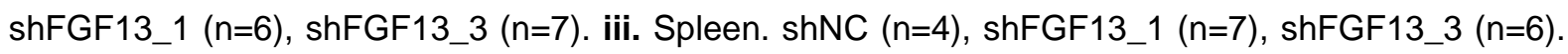
One-way ANOVA $P$ values are shown. ${ }^{*}, P<0.01$ (shFGF13_1 vs. shNC control). E\&F. Pancytokeratin (AE1/AE3) staining (brown) of metastatic deposits in secondary organs from mice inoculated with MDA-MB-231HMneoLUC-derived stable transfectants E. Lung. F. Liver. i. shNC, ii. shFGF13_1. Scale bar $200 \mu \mathrm{m}$.

This article is protected by copyright. All rights reserved. 
This article is protected by copyright. All rights reserved. 
$\mathrm{Ai}$

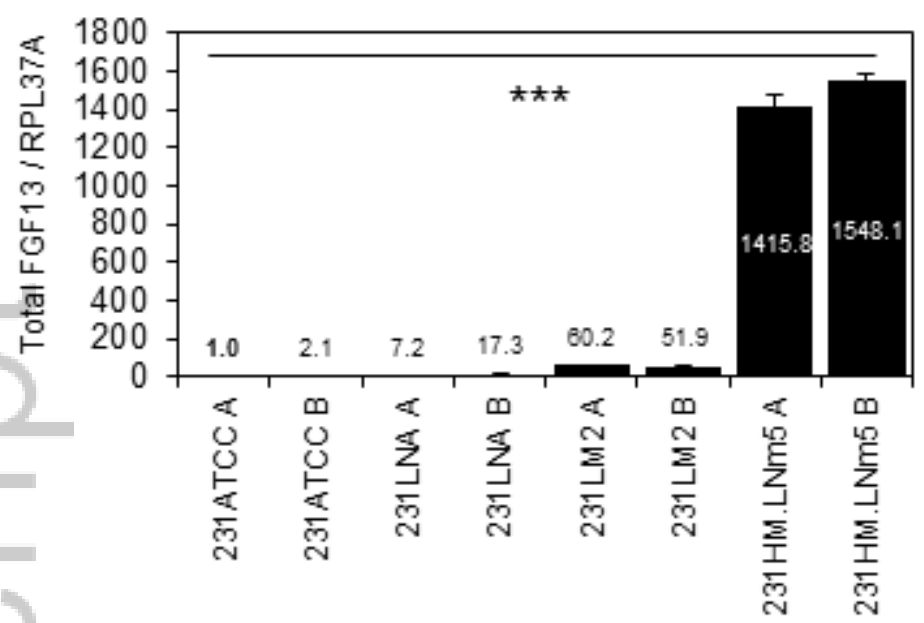

B

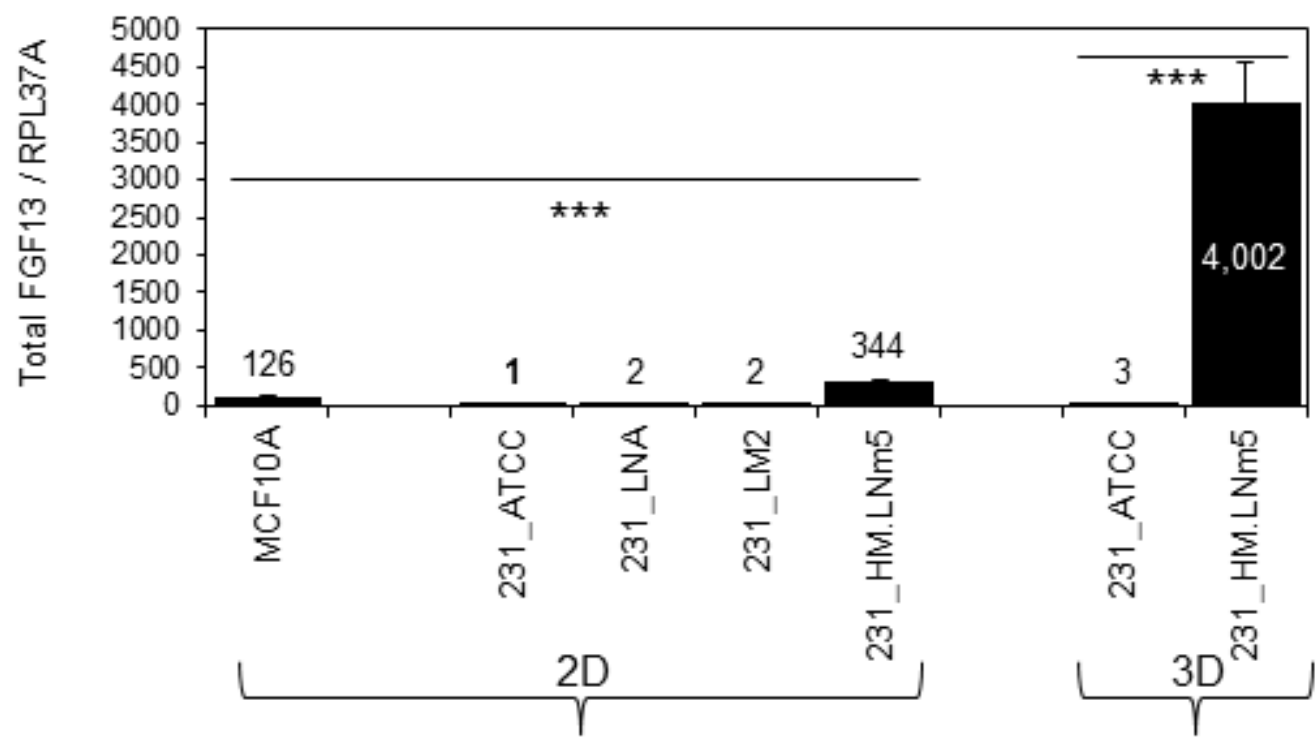

C

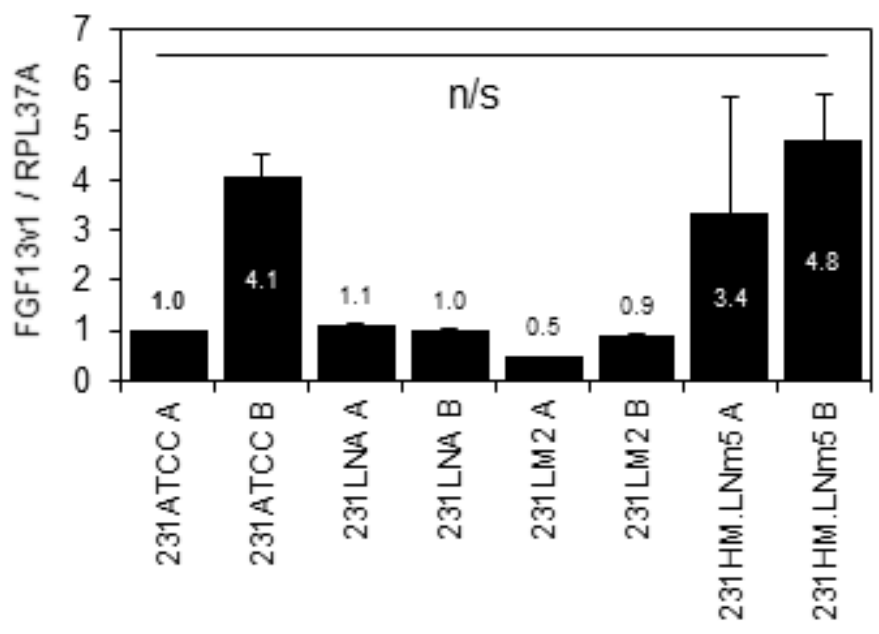

Figure 1

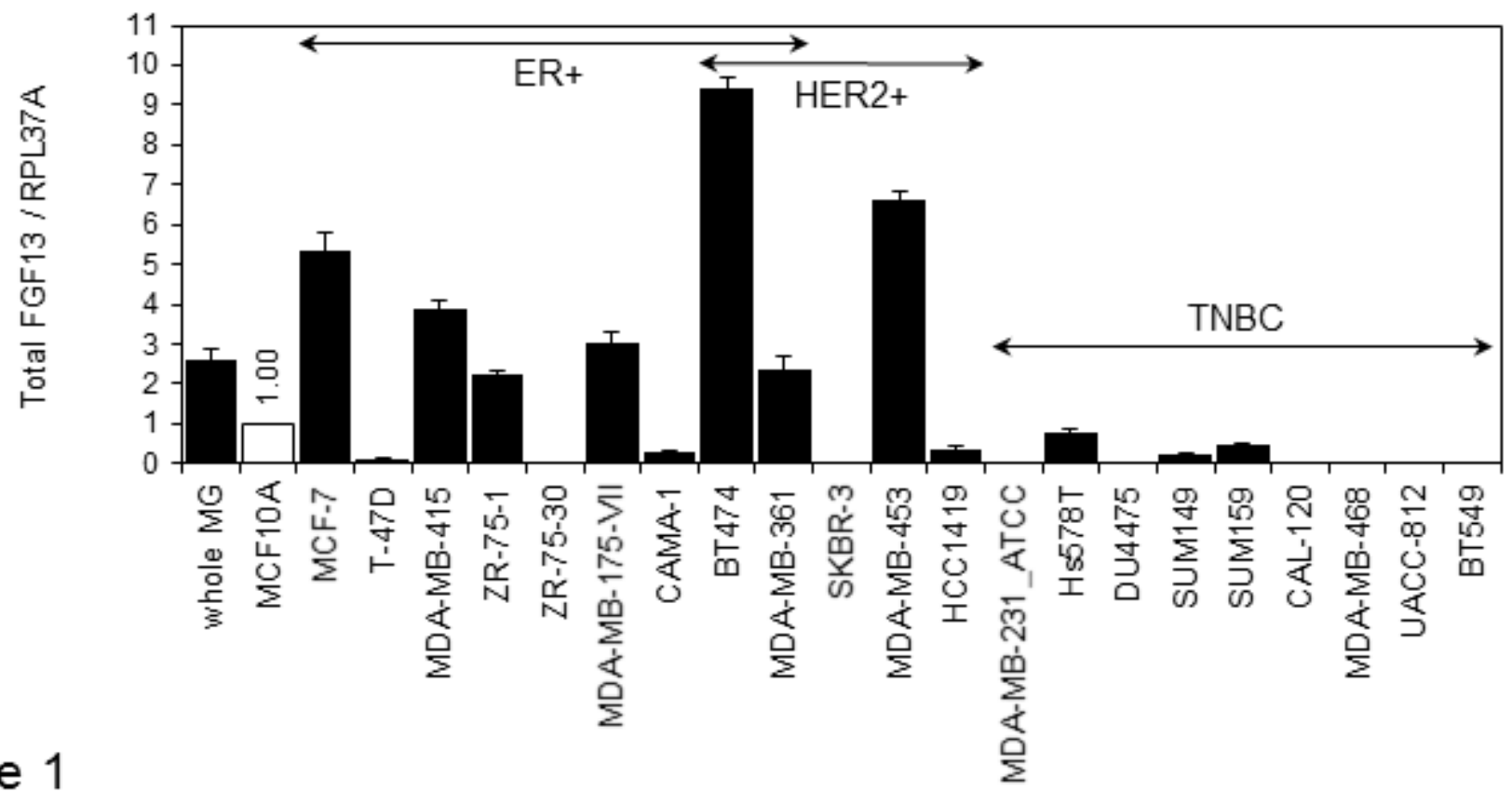

This article is protected by copyright. All rights reserved. 
A

R.F.S. All

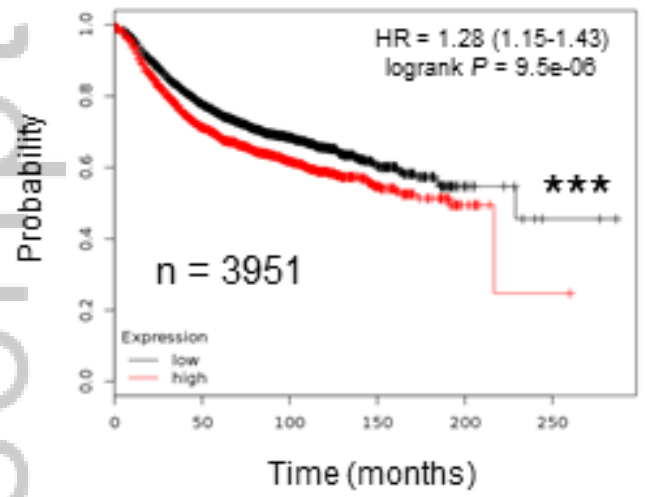

C R.F.S. Luminal A

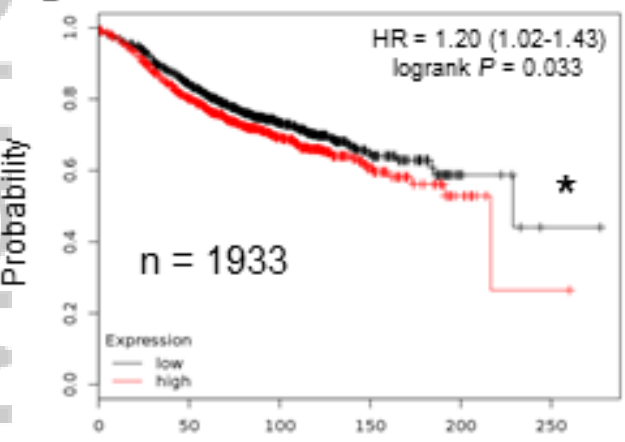

Time (months)

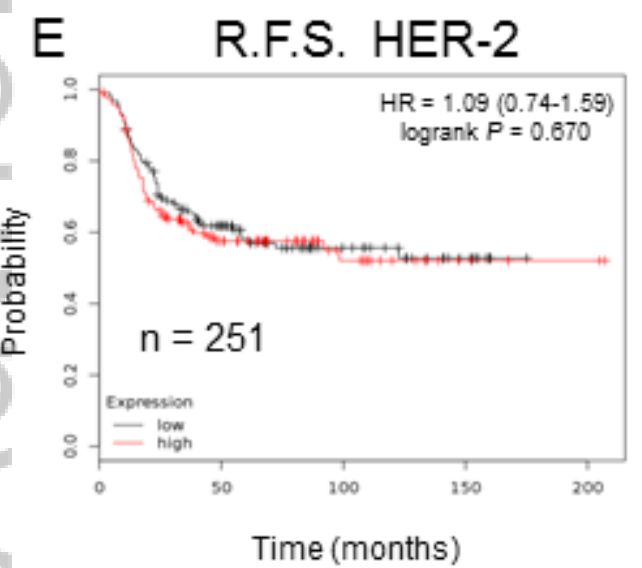

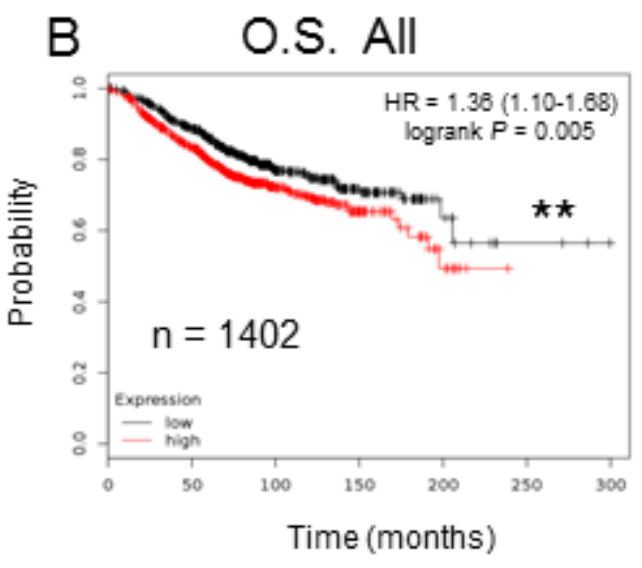
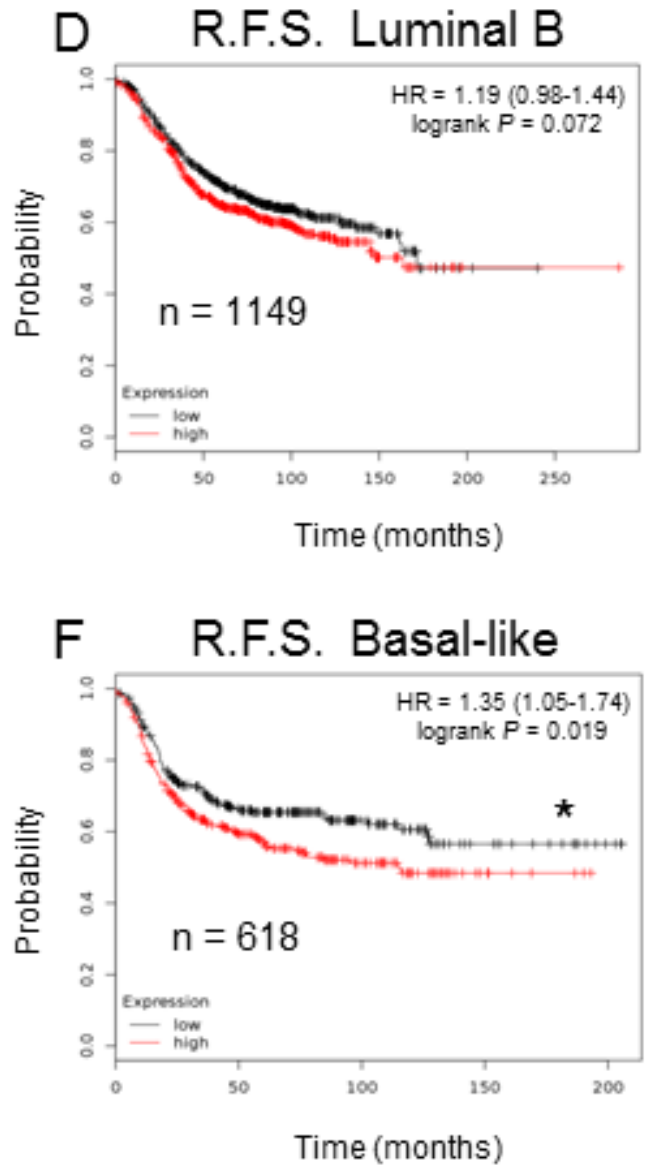

Luminal A $49 \%$ Luminal B $29 \%$ HER2+ $\quad 6 \%$ Basal $\quad 16 \%$ 
Novelty \& Impact Statement: IJC-19-1612.R2

Triple-negative breast cancer (TNBC) has a high degree of molecular diversity, with multiple subtypes and varying metastatic behavior. To better understand TNBC heterogeneity, the authors of this study performed RNA expression analysis on four isogenic MDA-MB-231 human TNBC tumor models characterized by distinct metastatic capacities. All four variants exhibited upregulation of the fibroblast growth factor FGF13. Elevated FGF13 expression was associated with poor survival in patients with basal-like breast cancer. In mice, FGF13 knockdown in highly metastatic MDA-MB-231 cells reduced spontaneous metastasis to liver and lung without affecting primary xenograft growth, suggesting that FGF13 is a promising antimetastatic target. 

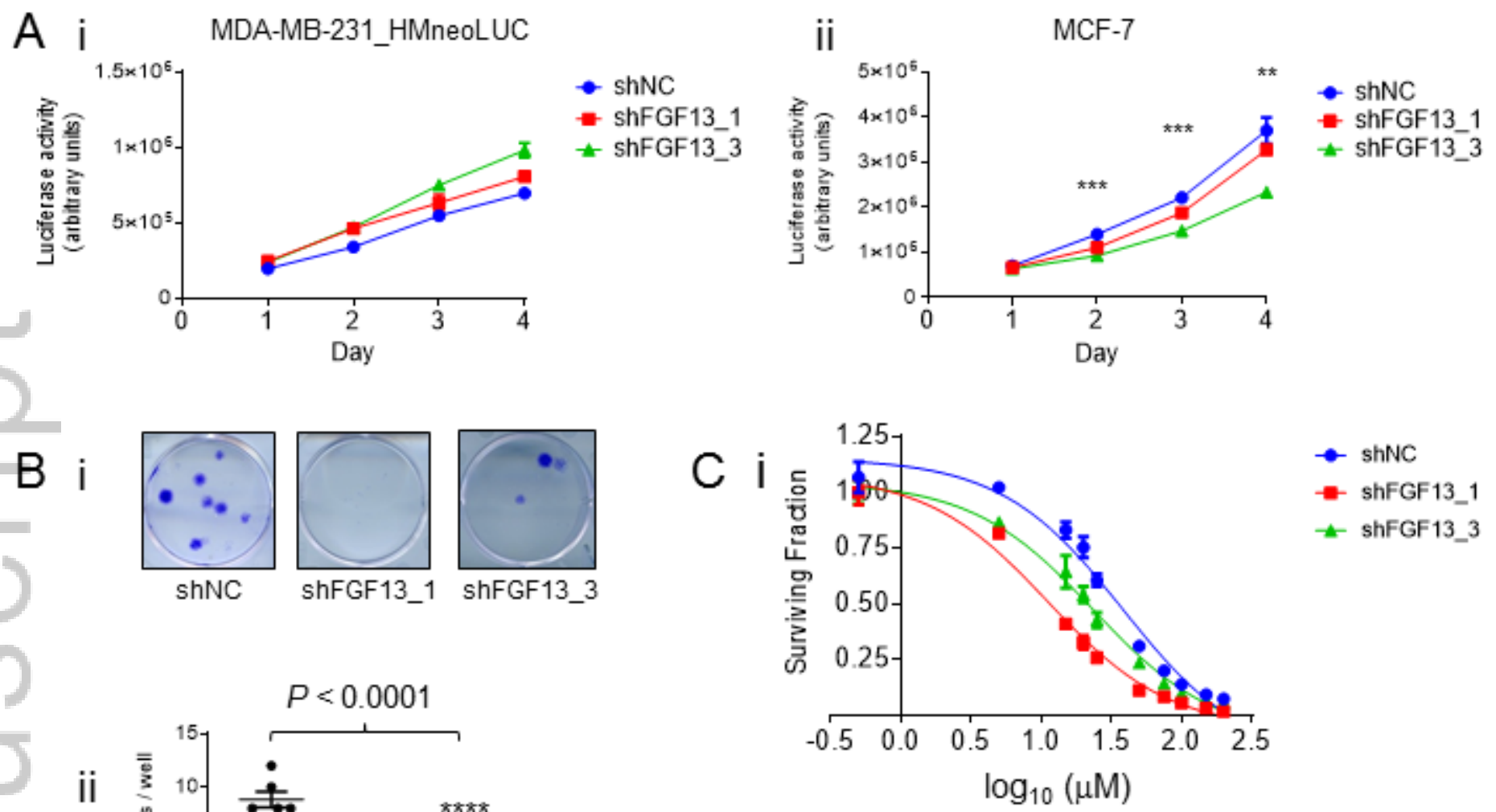

$\rightarrow$ shNC

- shFGF13_1

- shFGF13_3
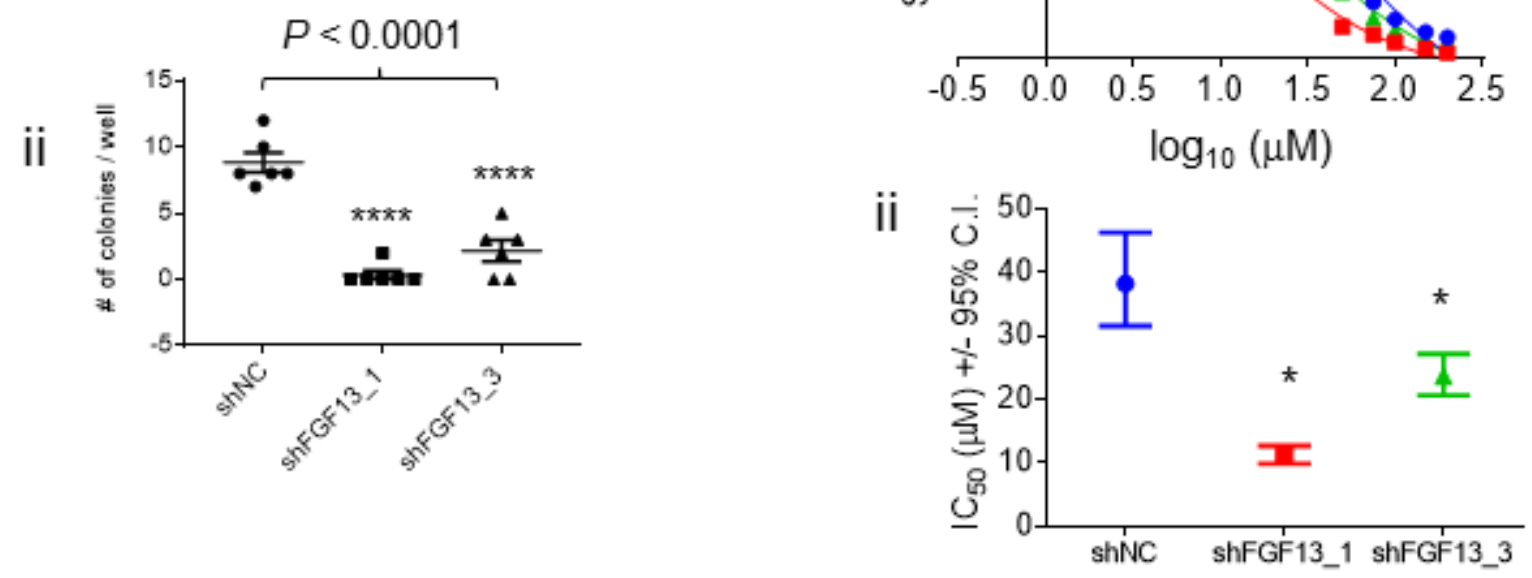

D
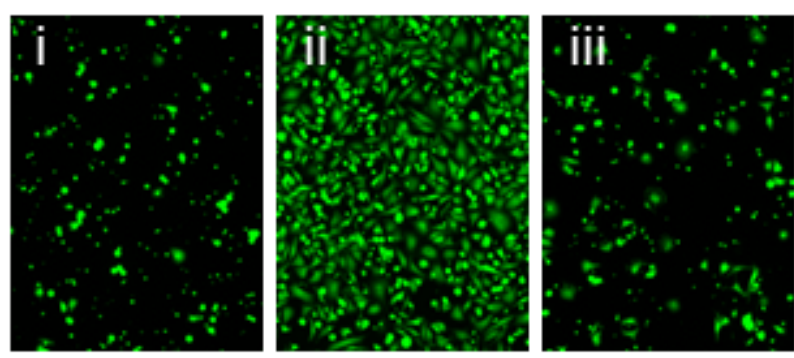
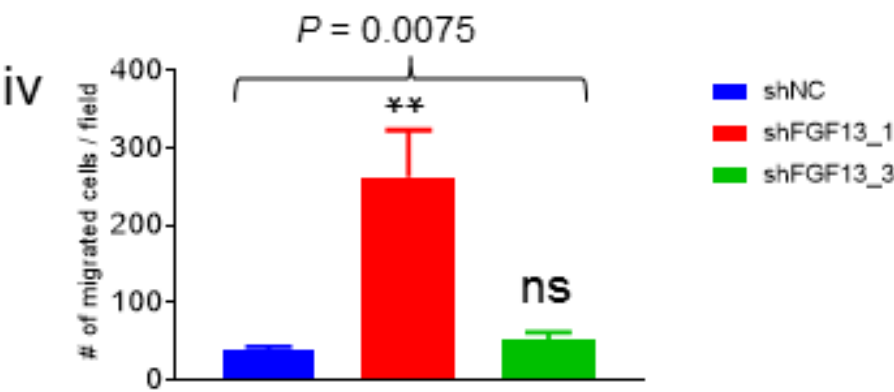

$\operatorname{shNC}$
shFGF13_1
shFGF13 3

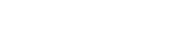

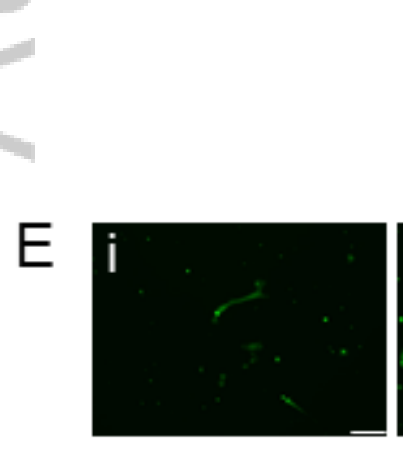
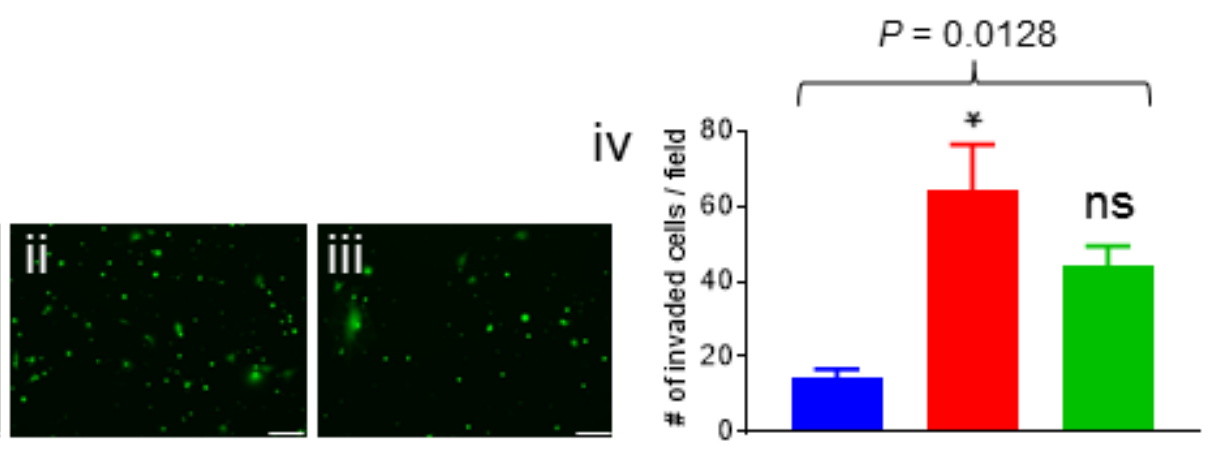

Figure 3

This article is protected by copyright. All rights reserved. 
Figure 4

A. i. $s h N C$
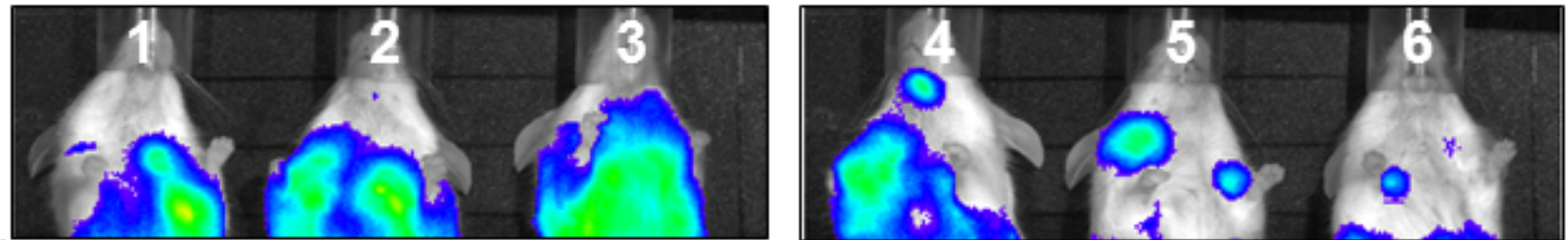

ii. shFGF13 1
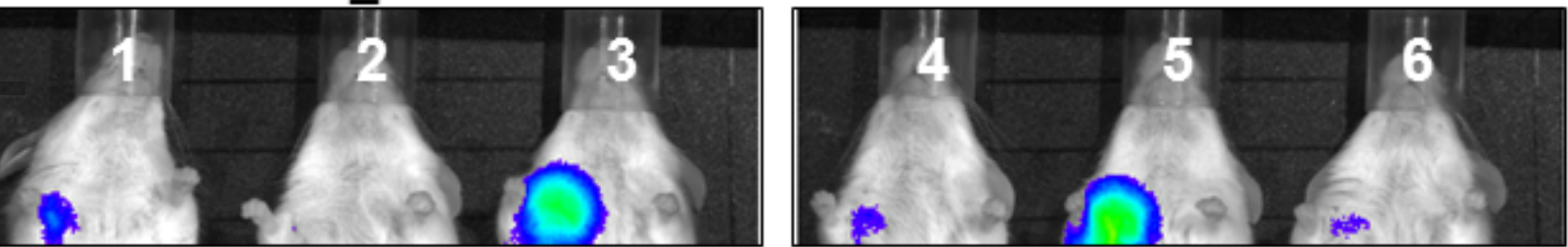

iii. shFGF13 3
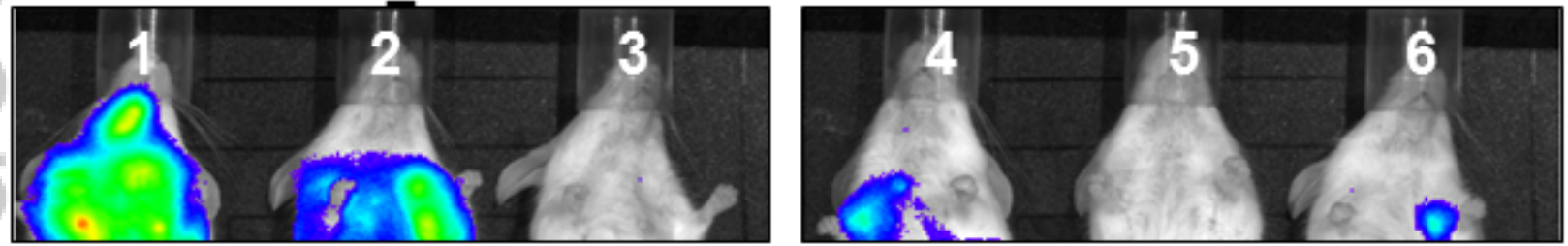

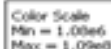

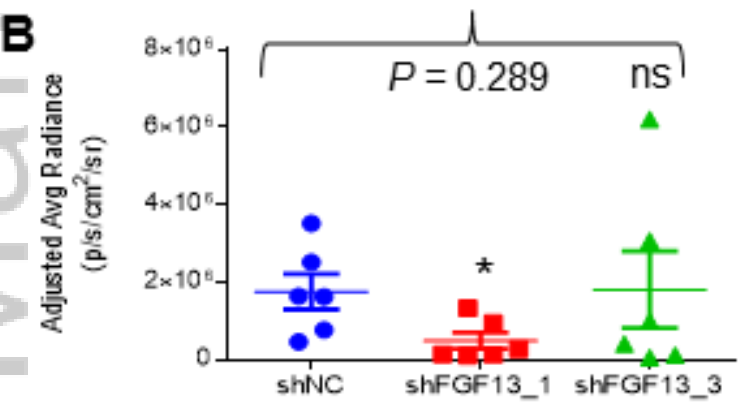

C
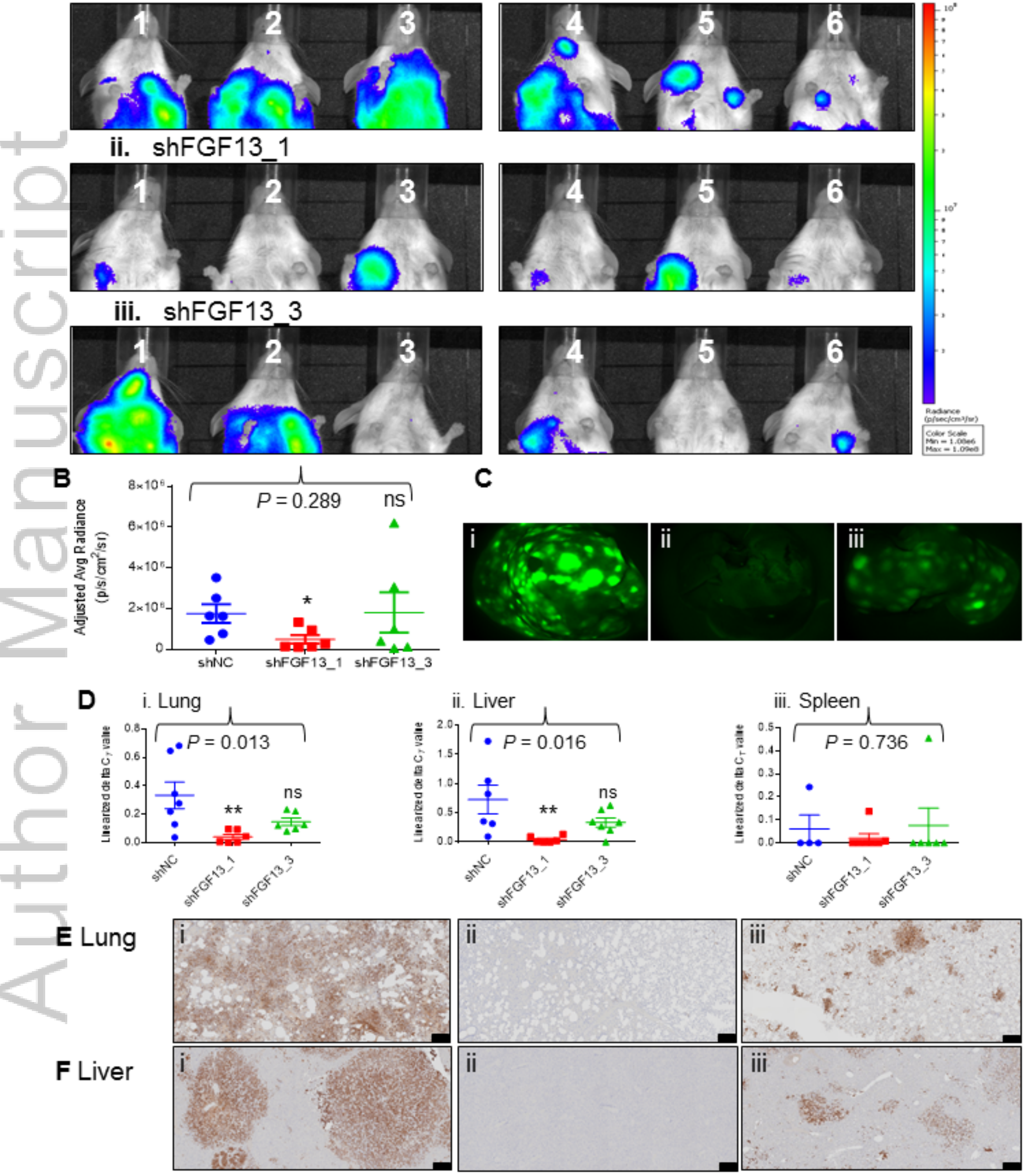


\section{University Library}

\section{- M M N E R VA A gateway to Melbourne's research publications}

Minerva Access is the Institutional Repository of The University of Melbourne

Author/s:

Johnstone, CN;Pattison, AD;Harrison, PF;Powell, DR;Lock, P;Ernst, M;Anderson,

$\mathrm{RL}$;Beilharz, TH

Title:

FGF13 promotes metastasis of triple-negative breast cancer

Date:

2020-02-24

\section{Citation:}

Johnstone, C. N., Pattison, A. D., Harrison, P. F., Powell, D. R., Lock, P., Ernst, M., Anderson, R. L. \& Beilharz, T. H. (2020). FGF13 promotes metastasis of triple-negative breast cancer. INTERNATIONAL JOURNAL OF CANCER, 147 (1), pp.230-243. https://doi.org/10.1002/ ijc.32874.

Persistent Link:

http://hdl.handle.net/11343/275454 